\title{
Mitigation potential and global health impacts from emissions pricing of food commodities ${ }^{*}$
}

\section{Supplementary information}

\section{Table of Contents}

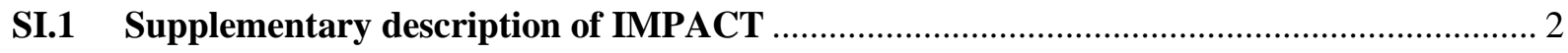

SI.2 Supplementary methods on linking agricultural and health analyses......................... 14

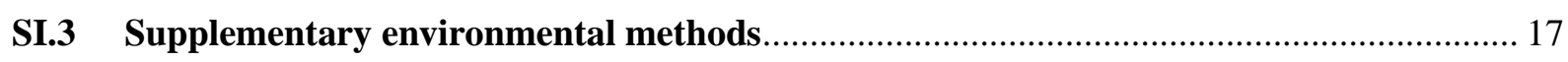

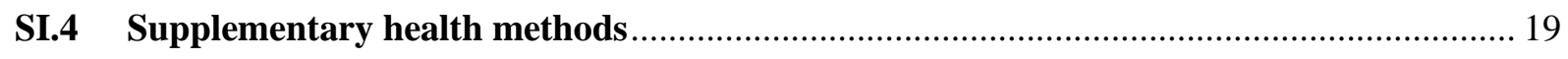

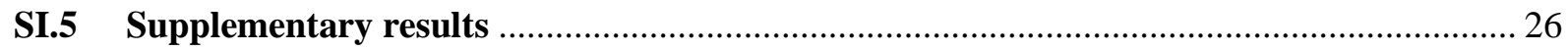

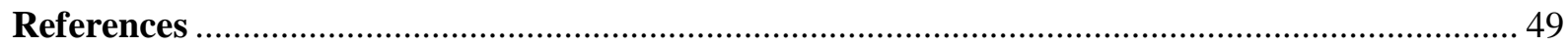

* Please note that this is the final author version (the authors' accepted version of their manuscript) of the Supplementary Information. Nature Climate Change holds the copyright of the published article which can be accessed via http://dx.doi.org/10.1038/nclimate3155. 


\section{SI.1 Supplementary description of IMPACT}

The International Model for Policy Analysis of Agricultural Commodities and Trade (IMPACT) uses economic, water, and crop models to simulate global food production, consumption, and trade of 62 agricultural commodities for over 150 world regions ${ }^{1}$. The regional aggregation used in this study is listed in Supplementary Table 1. For this study, we used the IMPACT model to produce global food scenarios for the year 2020, and we relied on its demand system to estimate changes in food demand resulting from levying greenhouse gas (GHG) taxes on food commodities.

The IMPACT model system is organized around a core global partial equilibrium multimarket model of agricultural production, demand, trade, and prices. The multi-market model simulates the operation of national and global markets for agricultural commodities, solving for equilibrium prices and quantities. The model specifies supply and demand behaviour in all markets. The following sections describe the elements of the model.

\section{Crop Production}

Crop production in IMPACT is simulated through area and yield response functions. (In IMPACT, area is treated as harvested area, which is the total area planted and harvested within a year, and may include multi-cropping or multiple harvests and differ from total arable land or reported physical area). The choice of specifying crop production in this way has a long history in IMPACT and facilitates interaction with commodity experts and land-use specialists, who work in natural units (hectares, tons/hectare). Crop production in IMPACT is specified sub-nationally with the area and yield functions at the level of Food Production Units (FPU). This regional disaggregation permits linking with water models and provides the added benefit of smaller geographical units for aggregating climate change results, which can vary significantly from one location to another. Land used for crop production is divided into irrigated and rainfed systems, capturing the significant differences in yields observed across these cultivation systems and linking directly with the water models which treat irrigated and rainfed water supplies separately.

IMPACT 3 includes the implementation of a land market to manage competing demands for agricultural land from different crops, as well as providing new linkage points to land-use models that work with broader land-use changes, such as conversion of forest to grasslands and agricultural land. It also allows us to separate total area supply (irrigated and rainfed) from individual crop area demands, and allows equilibrium conditions to determine the best economic use of the available land. The total supply of land is assumed to be a function of the "scarcity value" or "shadow price index" of land, which can also be considered a summary of changes in crop prices. The shadow price (WF) is indexed to 1 in the first year and changes based on changing demands from all crops for land area. 


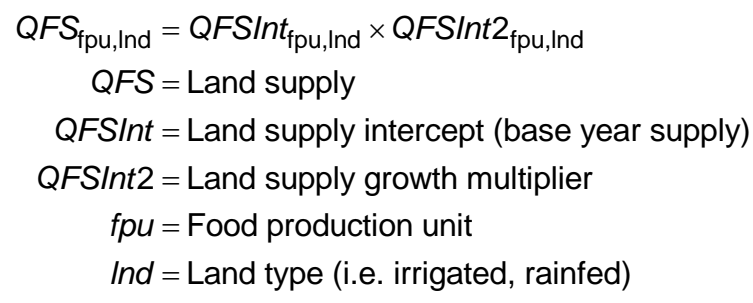

The supply of land is considered exogenous within each year, meaning that farmers are not allowed to adjust the total crop area in the middle of the year. The total land supply over time is driven by exogenous trends on the availability of area for agriculture, as well as endogenous responses to changes in area demand, which is handled in between years. The following equation is applied at the end of each year before solving for a new year.

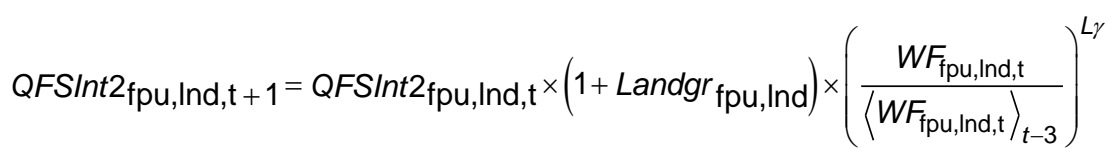

$$
\begin{aligned}
& \text { Landgr = Exogenous land supply growth rate } \\
& \left\langle W F_{\text {fpu, Ind, }}\right\rangle_{t-3}=\text { Average shadow price of past } 3 \text { years } \\
& L \gamma=\text { Land supply elasticity }
\end{aligned}
$$

Crop area is specified as an area demand function with respect to changes in the marginal revenue product, changes in land cost, and exogenous non-price trends in harvested area. Crop area elasticities simulate the supply response to changes in the marginal revenue of land represented by the following equation as the interaction of the net price of an activity and the productivity of the activity in using an additional hectare of land.

$$
\begin{aligned}
M R P_{\mathrm{j}, \mathrm{fpu}, \text { Ind }} & =Y \mathrm{Yd}_{\mathrm{j}, \mathrm{fpu}, \text { Ind }} \times P N E T_{\mathrm{j}, \mathrm{cty}} \\
M R P & =\text { Marginal revenue product of land } \\
Y I d & =\text { Crop yield } \\
P N E T & =\text { Net price for the activity at the country-level mapped to fpu } \\
j & =\text { Activity (crop) } \\
c t y & =\text { Country }
\end{aligned}
$$

The exogenous trend in harvested area captures changes in area resulting from factors other than direct market effects, such as government programs encouraging cropping expansion, or contraction due to soil degradation, or conversion of land from agriculture to nonagricultural uses. The combination of these endogenous and exogenous factors in area demand are described in the following equation.

$$
\begin{aligned}
\text { Area } a_{\mathrm{j}, \mathrm{fpu}, \text { Ind }} & =\text { Arealnt } \mathrm{j}_{\mathrm{j} \text { fpu, Ind }} \times \text { Arealnt }_{\mathrm{j}, \mathrm{fpu}, \text { Ind }} \times W F_{\mathrm{fpu}, \text { Ind }} W F_{\varepsilon} \times\left(\frac{M R P_{\mathrm{j}, \mathrm{fpu}}}{M R P 0_{\mathrm{j}, \mathrm{fpu}}}\right)^{A \varepsilon} \\
A r e a & =\text { Final crop area } \\
\text { Arealnt } & =\text { Crop area intercept (base year crop area) } \\
\text { Arealnt2 } & =\text { Exogenous crop area growth multiplier } \\
W F \varepsilon & =\text { Elasticity of demand with respect to land shadow price } \\
M R P 0 & =\text { Base year marginal revenue product (used to index prices) } \\
A \varepsilon & =\text { Elasticity of area demand with respect to marginal revenue product }
\end{aligned}
$$

Assumptions for exogenous trends are determined by a combination of historical changes in land use and expert judgment on potential future regional dynamics. They are represented as compound growth from the base and are applied between years. 


$$
\begin{aligned}
& \text { Arealnt2j,fpu,Ind,t+1 }=\text { Arealnt2j,fpu,Ind, } \mathrm{t} \times\left(1+\text { Areagr }_{\mathrm{fpu}, \mathrm{Ind}}\right) \\
& \text { Areagr }=\text { Exogenous area demand growth rate }
\end{aligned}
$$

Competing demands from different crops are handled through an equilibrium equation that determines the land allocation and ensures that all crop area demand must sum up to the total land supply for each FPU.

$$
Q_{\text {fpu }, \text { Ind }}=\sum_{j} A_{j} a_{j, f p u, I n d}
$$

Crop yields are a function of commodity prices, prices of inputs, available water, climate, and exogenous trend factors. The IMPACT model includes four ways that changes in yields are achieved. First, the model assumes a scenario of underlying improvements in yields over time that, to varying degrees, continue trends observed over the past 50-60 years in an informed extrapolation following the concepts introduced in Evenson and Rosegrant ${ }^{2}$, and Evenson and colleagues $^{3}$. These long-run trends, or intrinsic productivity growth rates (IPRs), are intended to reflect the expected increases in inputs, improved seeds, and improvements in management practices. These trends differ and are generally higher for developing countries, where there is considerable scope to narrow the gap in yields compared to developed countries. These IPRs are exogenous to the model, and changes in them are specified as part of the definition of different scenarios. We assume that these underlying trends vary by crop and region, and that they will decline somewhat over the next fifty years as the pace of technological improvements in developed countries slows, and as developing countries "catch up" to yields in developed countries.

Second, the IMPACT model includes a short-run (annual), endogenous, response of yields to changes in both input and output prices. These yield response functions specify the change in yield as a constant elasticity function of the changes in output prices, with elasticity parameters that can vary by crop and region. The underlying assumption is that farmers will respond to changes in prices by varying the use of inputs, including inputs such as fertilizer, chemicals, and labour that will, in turn, change yields.

Third, climate is assumed to affect yields through two mechanisms. The first mechanism is through the effects of changes in temperature and "weather" due to climate change on crop yields for rainfed and irrigated crops, as calculated from the solution of a crop simulation model (DSSAT ${ }^{4,5}$ ) for different climate change scenarios. These crop simulations vary by crop type. The DSSAT model is run with detailed time, geographic, and crop disaggregation for different climate change scenarios that are "downscaled" to include weather variation over small geographic areas. This analysis gives changes in average yields due to climate change that are then averaged to generate yield shocks by crop and region (FPU) in the IMPACT model. These long-run climate scenarios generate yield shocks that are assumed to follow simple trends over time, and do not consider extreme events such as droughts or floods.

The fourth mechanism by which climate change affects yields is through variation in water availability for agriculture year-by-year under different climate scenarios. This mechanism is modelled through the use of the IMPACT water models. These include: (1) a global hydrology model that determines run off to the river basins included in the IMPACT model; (2) water basin management models for each FPU that optimally allocate available water to 
competing non-agricultural and agricultural uses, including irrigation; and (4) a water allocation and stress model that allocates available irrigation water to crops and, when the water supply is less than demand by crop, computes the impact of the water shortage on crop yields accounting for differences among crops and varieties. These yields shocks are then passed to the IMPACT model, affecting year-to-year crop yields.

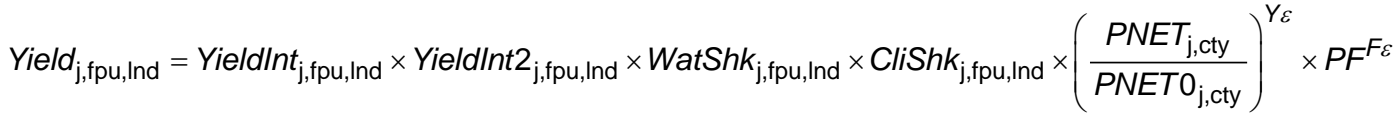

$$
\begin{aligned}
& \text { Yield }=\text { Final yield } \\
& \text { YieldInt }=\text { Yield intercept (base year yield) } \\
& \text { YieldInt2 }=\text { Exogenous yield growth multiplier } \\
& \text { WatShk }=\text { Water stress shock (from water models) } \\
& \text { CliShk = Climate change shock (from water and crop models) } \\
& Y \varepsilon=\text { Yield supply elasticity with respect to net price } \\
& P F=\text { Input prices } \\
& F_{\varepsilon}=\text { Yield supply elasticity with respect to input prices }
\end{aligned}
$$

Final crop production for each FPU and crop (j) is estimated as the product of the solution for its respective area and yield equations, with national production $\left(\mathrm{QS}_{\mathrm{j}, \text { cty }}\right)$ equal to the summation of the production in all of the relevant FPUs in that country.

$$
Q S_{\mathrm{j}, \mathrm{cty}}=\sum_{\mathrm{fpu}, \mathrm{Ind}}\left(\text { Area }_{\mathrm{j}, \mathrm{fpu}, \mathrm{Ind}} \times \text { Yield }_{\mathrm{j}, \mathrm{fpu}, \text { Ind }}\right)
$$

\section{Livestock Production}

Livestock production is modelled at the FPU level and includes animal numbers, with associated feed demands, and meat/dairy production based on "processing" the animals. Similar to the crop sector, this specification allows for easier translation of information from livestock experts who are used to working with herd-size and feeding requirements. In the current version of the model, there is no modelling of herd dynamics-herd size over time is set exogenously.

Feed demand is a function of the livestock's own price, the prices of intermediate (feed) inputs, and a trend variable reflecting growth in livestock herds (slaughter rates are implicitly assumed to stay more or less constant over time). The price elasticities in the livestock supply function are derived in a similar fashion to the crop area and yield elasticities.

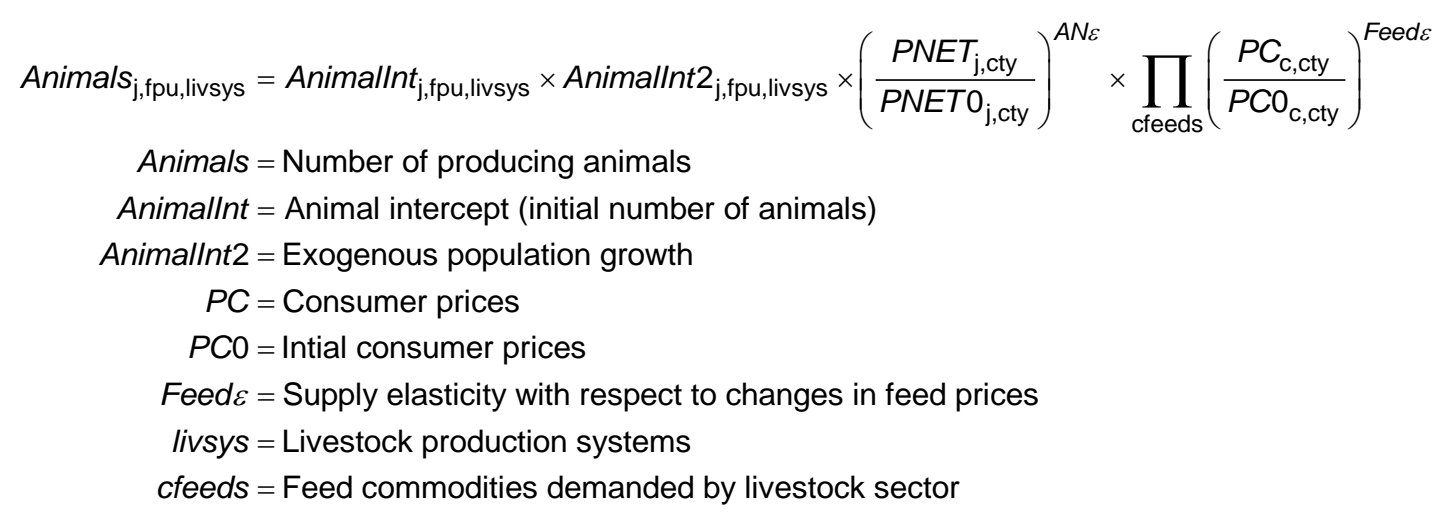


Livestock yields are determined through exogenous growth due to improved animals and management practices. Currently, all price responses in the livestock sector are accounted for in the animal number equations.

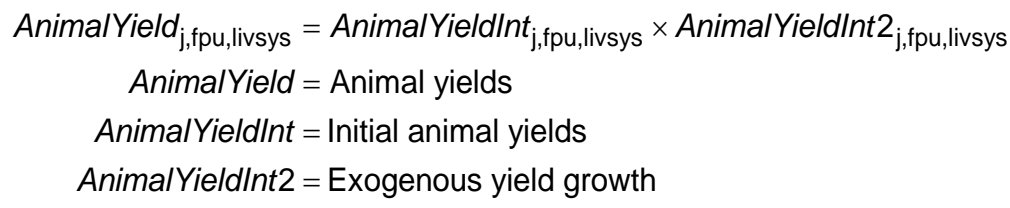

Total national production $\left(\mathrm{QS}_{\mathrm{j}, \mathrm{cty}}\right)$ is calculated by multiplying the slaughtered number of animals by the yield per head and summing across FPU and livestock system.

$$
Q S_{\mathrm{j}, \text { cty }}=\sum_{\text {fpu,livsys }}\left(\text { Animals }_{\mathrm{j}, \text { fpu,livsys }} \times \text { AnimalYield }_{\mathrm{j}, \text { fpu, livsys }}\right)
$$

\section{Production of Processed Goods}

Modelling of processed goods (i.e. food oils, oil meals, sugar) has been an active area of improvement for IMPACT 3, and the development of the activity-commodity framework allows for a general handling of all processed goods in IMPACT through Input-Output matrices (IOMATs) and the use of net prices. The IOMATs represent technical coefficients on input requirements and are specified by quantities of inputs per unit of output (i.e. mt of soybeans per mt of soybean oil), and are calculated from the base data. The net price is the price the producer receives net of input costs. The net price will equal the producer price of the activity whenever there are no intermediate inputs. (Crops and livestock currently do not include intermediate inputs in the PNET equation, and instead directly take input price effects through supply elasticities in the crop yield, and animal number equations).

$$
\begin{aligned}
P N E T_{\mathrm{j}, \text { cty }} & =P P_{\mathrm{j}, \text { cty }}-\sum_{\text {inputs }}\left(I O M A T_{\text {inputs, } \mathrm{j}, \mathrm{cty}} \times\left(1-C S E I_{\text {inputs,cty }}\right) \times P C_{\text {inputs,cty }}\right) \\
P N E T & =\text { Net price } \\
P P & =\text { Producer price } \\
P C & =\text { Consumer price of inputs } \\
C S E I & =\text { Consumer support estimate on intermediate inputs } \\
I O M A T & =\text { Input-output matrix } \\
\text { inputs } & =\text { Set of commodities (c) that are inputs into activity j }
\end{aligned}
$$

Production of processed goods are then simulated by a supply function that incorporates both endogenous price effects, as well as exogenous technological change. As opposed to crop and livestock production, processed goods are modelled at the country level instead of at the FPU.

$$
\begin{aligned}
Q S_{\mathrm{j}, \mathrm{cty}} & =Q S I n t_{\mathrm{j}, \text { cty }} \times Q S I N T 2_{\mathrm{j}, \text { cty }} \times\left(\frac{P N E T_{\mathrm{j}, \text { cty }}}{P N E T 0_{\mathrm{j}, \mathrm{cty}}}\right)^{Q S \varepsilon} \\
Q S & =\text { Total production } \\
Q S I n t & =\text { Initial production } \\
Q S I n t 2 & =\text { Exogenous productivity growth } \\
Q S \varepsilon & =\text { Supply elasticity with respect to net price }
\end{aligned}
$$

\section{Commodity Supply and Demand}

Total supply of commodities requires mapping from output of production activities to supply of commodities. The mapping is given by: 


$$
\begin{aligned}
\text { QSUP } & \\
\text { c,cty } & =\sum_{\mathrm{j}} J C R a t i o_{\mathrm{j}, \mathrm{c}} \times Q S_{\mathrm{j}, \mathrm{cty}} \\
\text { QSUP } & =\text { Total commodity supply } \\
J C R a t i o & =\text { Activity to commodity mapping } \\
c & =\text { Commodity } \\
c t y & =\text { Country }
\end{aligned}
$$

The parameter JCRatio maps from the activity output to commodities. Usually, each activity produces a matched commodity (e.g., wheat growing activity produces the commodity wheat, and nothing else). The specification, however, is general. There can be many activities producing the same commodity (e.g., different wheat growing activities producing the same wheat commodity) or a single activity producing more than one commodity (e.g., oil seed processing yielding both oil and meal). By convention, the units of $\mathrm{j}$ agree with the units of the main commodity produced by the activity (e.g., output of the wheat activity yields the commodity wheat, in the same units), so that the JCRatio for this mapped commodity always equals one. Other outputs, if any, from an activity in JCRatio are measured as a ratios to the output of the main activity (e.g., tons of meal per ton of production of oil in an oilseed processing plant).

Total domestic demand for a commodity is the sum of household food demand, agricultural intermediate demand (feed, and for process goods), and intermediate demand from other sectors (i.e. biofuels, and industrial uses).

$$
\begin{aligned}
Q D_{\mathrm{c}, \mathrm{cty}} & =\sum_{\mathrm{h}}\left(Q H_{\mathrm{c}, \mathrm{h}, \mathrm{cty}}\right)+\text { QInterm } \mathrm{c}, \mathrm{cty} \\
Q D & =\text { Total commodity demand } \\
Q H & =\text { Household food demand } \\
Q I n t e r m & =\text { Intermediate demand from Ag-processing sector } \\
Q L & =\text { Feed demand from livestock sector } \\
Q B F & =\text { Intermediate demand for biofuel feedstock } \\
Q O t h & =\text { All other demand } \\
h & =\text { Household type }
\end{aligned}
$$

Food demand is a function of the price of the commodity and the prices of other competing commodities, per capita income, and total population. Per capita income and population increase annually according to country-specific population and income growth rates. Population and GDP trends vary by scenario and are drawn from the Shared Socio-economic Pathway (SSP) database representing socio-economic scenarios from the IPCC's 5th assessment report. The IMPACT demand elasticities were originally based on elasticities estimated by the $\mathrm{USDA}^{6}$, and adjusted to represent a synthesis of average, aggregate elasticities for each region, given the income level and distribution of urban and rural population ${ }^{1}$. Own-price elasticities have been calibrated to a region-specific meta-analysis on the impacts of changes in food prices on food consumption ${ }^{7}$. Over time the elasticities are adjusted to accommodate the gradual shift in demand from staples to high value commodities like meat, especially in developing countries. This assumption is based on expected economic growth, increased urbanization, and continued commercialization of the agricultural sector. 


$$
\begin{aligned}
Q H_{\mathrm{c}, \mathrm{h}, \mathrm{cty}} & =Q H I n t_{\mathrm{c}, \mathrm{h}, \mathrm{cty}} \times\left(\frac{p c G D P_{\mathrm{h}, \mathrm{cty}}}{p c G D P 0_{\mathrm{h}, \mathrm{cty}}}\right)^{I n c \varepsilon} \times\left(\frac{\left(1-C S E_{\mathrm{c}, \mathrm{cty}}\right) \times P C_{\mathrm{c}, \mathrm{cty}}}{\left(1-C S E_{\mathrm{c}, \mathrm{cty}}\right) \times P C 0_{\mathrm{c}, \mathrm{cty}}}\right)^{H F \varepsilon} \\
& \times \prod_{c c \neq c}\left(\frac{\left(1-C S E_{\mathrm{cc}, \mathrm{cty}}\right) \times P C_{\mathrm{cc}, \mathrm{cty}}}{\left(1-C S E 0_{\mathrm{cc}, \mathrm{cty}}\right) \times P C 0_{\mathrm{cc}, \mathrm{cty}}}\right)^{H F \varepsilon} \times \frac{P o p H_{\mathrm{h}, \mathrm{cty}}}{P o p H 0_{h, c t y}} \\
Q H & =\text { Household food demand } \\
Q H I n t & =\text { Initial household food demand } \\
p c G D P & =\text { Per capita GDP } \\
p c G D P 0 & =\text { Initial per capita GDP } \\
C S E & =\text { Consumer support estimate } \\
C S E 0 & =\text { Initial consumer support estimate } \\
P O p H & =\text { Population disaggregated by household type } \\
P O p H O & =\text { Initial household population } \\
I n C \varepsilon & =\text { Income demand elasticity } \\
H F \varepsilon & =\text { Price demand elasticty } \\
\left(\frac{(1-C S E) \times P C}{(1-C S E 0) \times P C O}\right)^{H F \varepsilon} & =\text { Own-price response } \\
\prod_{c c \neq c}\left(\frac{(1-C S E) \times P C}{(1-C S E 0) \times P C 0}\right)^{H F \varepsilon}= & =\text { Cross-price response }
\end{aligned}
$$

Feed demand is a derived intermediate demand. It is determined by two components: (1) animal feed requirements determined by livestock production and livestock feed requirements and (2) price effects that take into account potential substitution possibilities among different feeds. The equation also incorporates a technology parameter that indicates improvements in feeding efficiencies over time.

$$
\begin{aligned}
Q L_{c, \mathrm{cty}} & =\sum_{\mathrm{jlvst}}\left(Q S_{\mathrm{j} \text { lvst,cty }} \times \operatorname{Re} q_{\mathrm{jlvst}, \mathrm{c}, \mathrm{cty}}\right) \times \prod_{\mathrm{cfeeds}}\left(\frac{P C_{\mathrm{c}, \mathrm{cty}}}{P C 0_{\mathrm{c}, \mathrm{cty}}}\right)^{L F D \varepsilon} \\
Q L & =\text { Total feed demand for livestock sector } \\
Q S & =\text { Total production of each livestock activity } \\
\operatorname{Re} q & =\text { Feed requirements for each livestock activity } \\
L F D \varepsilon & =\text { Price elasticity of demand for feed } \\
j / v s t & =\text { Set of livestock producing activities }
\end{aligned}
$$

Intermediate demand is a derived demand that is based on the demand for final processed goods, such as food oils and sugar. The input-output matrix determines the proportions of inputs (c) required for each producing activity $(\mathrm{j})$.

$$
\begin{aligned}
\text { QDInterm } & \\
\mathrm{c}, \mathrm{cty} & =\sum_{\mathrm{j}}\left(\text { IOMat }_{\mathrm{c}, \mathrm{j}, \mathrm{cty}} \times Q S_{\mathrm{j}, \mathrm{cty}}\right) \\
Q D \text { Interm } & =\text { Intermediate demand } \\
\text { IOMat } & =\text { Input-Output matrix }
\end{aligned}
$$

Exogenous biofuel feedstock demand is determined through exogenous growth rates which represent government mandates to encourage the production of biofuels, though adjusted in various scenarios where the mandates are infeasible, or adjusted to reflect scenarios on the role of first or second generation biofuels. The biofuel feedstock demand equation also allows for a price response for biofuels to allow for substitution across different potential feedstocks, 
as well as to reflect the reality that increasing food prices would put pressure to ease biofuel mandates.

$$
\begin{aligned}
Q B F_{\mathrm{c}, \mathrm{cty}} & =Q B F I n t_{\mathrm{c}, \mathrm{cty}} \times Q B F I N T 2_{\mathrm{c}, \mathrm{cty}} \times \prod_{\mathrm{c}}\left(\frac{P C_{\mathrm{c}, \mathrm{cty}}}{P C 0_{\mathrm{c}, \mathrm{cty}}}\right)^{B F \varepsilon} \\
Q B F & =\text { Biofuel feedstock demand } \\
Q B F I n t & =\text { Initial demand from biofuel sector } \\
Q B F I n t 2 & =\text { Exogenous growth in demand from biofuels } \\
B F \varepsilon & =\text { Price elasticity of demand for biofuel feedstock }
\end{aligned}
$$

Other demand summarizes all other demands for agricultural products from sectors outside of the focus of IMPACT (e.g. seeds, industrial use, etc.). It is simulated under two different equations. The primary method follows the household food demand equation, and is sensitive to changes in income, population and prices.

$$
\begin{aligned}
Q O t h_{\mathrm{c}, \mathrm{cty}} & =Q O \operatorname{thInt}_{\mathrm{c}, \mathrm{cty}} \times\left(\frac{p c G D P_{\mathrm{cty}}}{p c G D P 0_{\mathrm{cty}}}\right)^{I O t h \varepsilon} \times\left(\frac{P O P_{\mathrm{cty}}}{P O P 0_{\mathrm{cty}}}\right) \times \prod_{c c}\left(\frac{P C_{\mathrm{c}, \mathrm{cty}}}{P C 0_{\mathrm{c}, \mathrm{cty}}}\right)^{P O \text { th } \varepsilon} \\
\text { QOth } & =\text { Other Demand } \\
\text { Q thInt } & =\text { Initial other demand } \\
\text { IOth } \varepsilon & =\text { Income demand elasticity for other demand } \\
\text { POth } \varepsilon & =\text { Price demand elasticity for other demand }
\end{aligned}
$$

\section{Markets, Trade, and Equilibrium Prices}

The system of equations is written in the General Algebraic Modeling System (GAMS) programming language ${ }^{8}$. The solution of these equations is achieved by the Path solver, which is included in the GAMS system. This procedure finds a set of domestic and world prices for all crops that "clear" domestic and international commodity markets. The world price (PW) of a commodity is the equilibrating mechanism for traded commodities — when an exogenous shock is introduced in the model, PW will adjust to clear world markets and each adjustment is passed back to the effective producer (PS) and consumer (PD) prices via the price transmission equations. Changes in domestic prices subsequently affect commodity supply and demand, necessitating their iterative readjustments until world supply and demand balance and world net trade again equals zero. For non-traded commodities, domestic prices in each country adjust to equate supply and demand within the country.

IMPACT assumes a closed world economy - at the end of every year the world's production must equal the world's demand. This constraint is ensured by the following equation, where the sum of net trade over the globe must equal zero.

$$
\begin{aligned}
\sum_{\text {cty }} N T_{\mathrm{c}, \mathrm{cty}} & =0 \\
N T & =\text { Net Trade }
\end{aligned}
$$

National production and demand for tradable commodities are linked to world markets through trade. Commodity trade by country (cty) is a function of domestic production, domestic demand, and stock change. (Note that stocks are constant and exogenous). Regions with positive net trade are net exporters, while those with negative values are net importers. This specification does not permit a separate identification of international trade by country of origin and destination — all countries export to and import from a single global market. 


$$
\begin{aligned}
N T_{\mathrm{c}, \mathrm{cty}} & =Q S U P_{\mathrm{c}, \mathrm{cty}}-Q D_{\mathrm{c}, \mathrm{cty}}-Q S t_{\mathrm{c}, \mathrm{cty}} \\
N T & =\text { Net trade } \\
Q S t & =\text { Change in stocks }
\end{aligned}
$$

Prices are endogenous in the system of equations for food, and are calibrated to year 2005 commodity prices ${ }^{10-12}$. Price data were based on the Agricultural Market Access Database (AMAD) of commodity prices ${ }^{11}$, adjusted for the effect of trade policy represented by taxes and tariffs, price policies expressed in terms of producer support estimates (PSE), consumer support estimates (CSE), and the cost of moving products from one market to another represented by marketing margins (MM). Export taxes and import tariffs are drawn from GTAP data (Global Trade Analysis Project at Purdue University) and reflect trade policies at the national level ${ }^{12-14}$. PSEs and CSEs represent public policies to support production and consumption by creating wedges between world and domestic prices. PSEs and CSEs are based on OECD estimates and are adjusted by expert judgment to reflect regional trade dynamics ${ }^{15}$. Marketing margins (MM) reflects other factors such as transport and marketing costs of getting goods to various markets and are based on expert opinion on the quality and availability of transportation, communication, and market infrastructure. We adopted the data on consumer prices for our consumption-based policy analysis.

In the model, PSEs, CSEs, and MMs are expressed as percentages (ad valorem) of the world price. To calculate producer prices the appropriate wedges are applied to the domestic consumer prices (PC) and represent the mark-up observed in domestic markets from the farmgate or factory-gate prices producers receive. The producer price of an activity is the weighted sum of the prices of the commodities associated with that activity.

$$
\begin{aligned}
P P_{\mathrm{j}, \mathrm{cty}} \times\left(1+M M \mathrm{~J}_{\mathrm{j}, \mathrm{cty}}\right) & =\left(1+P S E_{\mathrm{j}, \text { cty }}\right) \times \sum_{\mathrm{c}} J C R a{ }^{\prime} i_{\mathrm{j}, \mathrm{c}, \mathrm{cty}} \times P C_{\mathrm{c}, \mathrm{cty}} \\
P P & =\text { Producer price } \\
M M J & =\text { Farm(factory)-gate to domestic market Marketing Margin (MM) } \\
P S E & =\text { Producer support estimate, ad valorem component } \\
J C R a t i o & =\text { mapping from activities (j) to commodities (c) }
\end{aligned}
$$

How consumer prices are determined in IMPACT depends on the state of tradability of the commodity. Commodities can be specified as either tradable or non-tradable. Traded commodity prices are determined in international markets. Non-traded commodities, are those commodities whose prices are determined in national markets, without direct links to international markets. Examples include sugarcane, sugar beets, and grass, where all demand is intermediate demand from domestic sectors (sugar processing, and livestock). These commodity prices are determined endogenously by country and ensure that domestic supply equals domestic demand.

$$
Q S U P_{\mathrm{c}, \mathrm{cty}}=Q D_{\mathrm{c}, \mathrm{cty}}
$$

Non-traded commodity are indirectly linked to world markets through the demand for final products (i.e. sugar), and potential substitution from tradable commodities (i.e. grass and other feeds). 
Supplementary Table 1. Regional aggregation

\begin{tabular}{|c|c|c|}
\hline \multicolumn{3}{|l|}{ High-income countries (HIC) } \\
\hline Australia & Hungary & Portugal \\
\hline Austria & Iceland & Republic of Korea \\
\hline Belgium and Luxembourg & Ireland & Rest of Arab Peninsula \\
\hline Canada & Israel & Saudi Arabia \\
\hline Croatia & Italy & Slovakia \\
\hline Cyprus & Japan & Slovenia \\
\hline Czech Republic & Netherlands & Spain \\
\hline Denmark & New Zealand & Sweden \\
\hline Finland & Norway & Switzerland \\
\hline France & Other Caribbean & United Kingdom \\
\hline Germany & Other Southeast Asia & United States of America \\
\hline Greece & Poland & \\
\hline \multicolumn{3}{|c|}{ Upper middle-income countries (UMC) } \\
\hline Botswana & Dominican Republic & Baltic States \\
\hline Algeria & Jamaica & Kazakhstan \\
\hline Gabon & Mexico & Other Balkans \\
\hline Namibia & Panama & Romania \\
\hline South Africa & Peru & Russian Federation \\
\hline Argentina & Uruguay & Fiji \\
\hline Brazil & Venezuela (Bolivarian Republic of) & Malaysia \\
\hline Chile & Lebanon & Other Pacific Ocean \\
\hline Colombia & Libya & \\
\hline Costa Rica & Bulgaria & \\
\hline Cuba & Belarus & \\
\hline \multicolumn{3}{|c|}{ Lower middle-income countries (LMC) } \\
\hline Angola & Paraguay & Turkmenistan \\
\hline Côte d'Ivoire & El Salvador & Ukraine \\
\hline Cameroon & Djibouti & Bhutan \\
\hline Lesotho & Egypt & Indonesia \\
\hline Nigeria & Iran (Islamic Republic of) & India \\
\hline Other Atlantic Ocean & Jordan & Sri Lanka \\
\hline Other Indian Ocean & Pakistan & Thailand \\
\hline Swaziland & Sudan & Timor-Leste \\
\hline Belize & Syrian Arab Republic & China \\
\hline Bolivia (Plurinational State of) & Tunisia & Mongolia \\
\hline Ecuador & Albania & Philippines \\
\hline Guyanas South America & Armenia & Papua New Guinea \\
\hline Guatemala & Azerbaijan & \\
\hline Honduras & Georgia & \\
\hline Nicaragua & Republic of Moldova & \\
\hline
\end{tabular}




\begin{tabular}{|c|c|c|}
\hline Burundi & Mali & Afghanistan \\
\hline Benin & Mozambique & Yemen \\
\hline Burkina Faso & Mauritania & Kyrgyzstan \\
\hline Central African Republic & Malawi & Tajikistan \\
\hline Congo & Niger & Uzbekistan \\
\hline Eritrea & Senegal & Bangladesh \\
\hline Ethiopia & Sierra Leone & Myanmar \\
\hline Ghana & Chad & Nepal \\
\hline Guinea & Togo & Cambodia \\
\hline Gambia & United Republic of Tanzania & Lao People's Democratic Republic \\
\hline Guinea-Bissau & Uganda & Solomon Islands \\
\hline Kenya & Zambia & Viet Nam \\
\hline Liberia & Zimbabwe & \\
\hline Madagascar & Haiti & \\
\hline \multicolumn{3}{|c|}{ Low and middle-income countries of Africa (AFR_LMIC) } \\
\hline Algeria & Ghana & Other Atlantic Ocean \\
\hline Angola & Guinea & Other Indian Ocean \\
\hline Benin & Guinea-Bissau & Senegal \\
\hline Botswana & Kenya & Sierra Leone \\
\hline Burkina Faso & Lesotho & South Africa \\
\hline Burundi & Liberia & Swaziland \\
\hline Cameroon & Madagascar & Togo \\
\hline Central African Republic & Malawi & Uganda \\
\hline Chad & Mali & United Republic of Tanzania \\
\hline Congo & Mauritania & Zambia \\
\hline Côte d'Ivoire & Mozambique & Zimbabwe \\
\hline Eritrea & Namibia & \\
\hline Ethiopia & Niger & \\
\hline Gabon & Nigeria & \\
\hline Gambia & Senegal & \\
\hline \multicolumn{3}{|c|}{ Low and middle-income countries of the Eastern Mediterranean (EMR_LMIC) } \\
\hline Lebanon & Tunisia & \\
\hline Libya & Afghanistan & \\
\hline Djibouti & Yemen & \\
\hline \multicolumn{3}{|l|}{ Egypt } \\
\hline \multicolumn{3}{|l|}{ Iran (Islamic Republic of) } \\
\hline \multicolumn{3}{|l|}{ Iraq } \\
\hline \multicolumn{3}{|l|}{ Jordan } \\
\hline \multicolumn{3}{|l|}{ Pakistan } \\
\hline \multicolumn{3}{|l|}{ Sudan } \\
\hline \multicolumn{3}{|l|}{ Syrian Arab Republic } \\
\hline \multicolumn{3}{|c|}{ Low and middle-income countries of Europe (EUR_LMIC) } \\
\hline Bulgaria & Georgia & \\
\hline Belarus & Republic of Moldova & \\
\hline Baltic States & Turkmenistan & \\
\hline Kazakhstan & Ukraine & \\
\hline Other Balkans & Kyrgyzstan & \\
\hline Romania & Tajikistan & \\
\hline
\end{tabular}


Russian Federation

Uzbekistan

Albania

Armenia

Azerbaijan

Low and middle-income countries of South-East Asia (SEA_LMIC)

Bhutan

Indonesia

India

Sri Lanka

Thailand

Timor-Leste

Bangladesh

Myanmar

Nepal

Low and middle-income countries of the Western Pacific (WPR_LMIC)

Fiji Solomon Islands

Malaysia

Other Pacific Ocean

China

Mongolia

Philippines

Papua New Guinea

Viet Nam

Cambodia

Lao People's Democratic Republic 


\section{SI.2 Supplementary methods on linking agricultural and health analyses}

\section{Conversion from food demand into food consumption}

Baseline food production and availability, as estimated by the IMPACT model, are calibrated using food balance sheets supplied by the Food and Agriculture Organization of the United Nations (FAO). The FAO ${ }^{16-18}$ states that:

The quantities of food available for human consumption, as estimated in the food balance sheet, relate to the quantities of food reaching the consumer. Waste on the farm and during distribution and processing is taken into consideration as an element in the food balance sheet. However, The amount of food actually consumed may be lower than the quantity shown in the food balance sheet depending on the degree of losses of edible food and nutrients in the household, e.g. during storage, in preparation and cooking (which affect vitamins and minerals to a greater extent than they do calories, protein and fat), as plate-waste, or quantities fed to domestic animals and pets, or thrown away.

For the dietary risk assessment, we converted the food availability estimates into food consumption estimates by using regional data on food wastage at the consumption level, combined with conversion factors into edible matter ${ }^{19}$. Supplementary Table 2 lists the waste percentages and conversion factors used. No conversion factor was used for red meat, because the waste percentages reported in Supplementary Table 2 were obtained for carcass weight (including bone), and therefore included wastage of non-edible parts.

Supplementary Table 2. Waste percentages at consumption according to FAO ${ }^{19}$

\begin{tabular}{|c|c|c|c|c|c|c|c|}
\hline Food items & Europe & $\begin{array}{c}\text { USA, } \\
\text { Canada, } \\
\text { Oceania }\end{array}$ & $\begin{array}{l}\text { Industri- } \\
\text { alized } \\
\text { Asia }\end{array}$ & $\begin{array}{c}\text { Sub- } \\
\text { Saharan } \\
\text { Africa }\end{array}$ & $\begin{array}{l}\text { North } \\
\text { Africa, } \\
\text { West and } \\
\text { Central } \\
\text { Asia }\end{array}$ & $\begin{array}{c}\text { South and } \\
\text { Southeast } \\
\text { Asia }\end{array}$ & $\begin{array}{c}\text { Latin } \\
\text { America }\end{array}$ \\
\hline Cereals & 0.25 & 0.27 & 0.2 & 0.01 & 0.12 & 0.03 & 0.1 \\
\hline Roots and tubers & 0.17 & 0.3 & 0.1 & 0.02 & 0.06 & 0.03 & 0.04 \\
\hline Oilseeds and pulses & 0.04 & 0.04 & 0.04 & 0.01 & 0.02 & 0.01 & 0.02 \\
\hline Fruits and vegetables & 0.19 & 0.28 & 0.15 & 0.05 & 0.12 & 0.07 & 0.1 \\
\hline Meat & 0.11 & 0.11 & 0.08 & 0.02 & 0.08 & 0.04 & 0.06 \\
\hline Milk & 0.07 & 0.15 & 0.05 & 0.001 & 0.02 & 0.01 & 0.04 \\
\hline
\end{tabular}

Conversion factors into edible matter: 0.82 for roots, 0.79 for maize, 0.78 for wheat, 1 for rice, 0.78 for other grains, 0.77 for fruits and vegetables, 1 for meat, 1 for oilseeds and pulses, 1 for milk 


\section{Weight estimation}

For the weight-related risk assessment, we estimated changes in weight as shifts in the baseline weight distribution by using the historical relationship between national food availability and mean BMI. We estimated the baseline distribution by fitting a log-normal distribution to WHO estimates of mean BMI and the prevalence of overweight and obesity using a cross-entropy method ${ }^{20}$. Cross-entropy estimation is a Bayesian technique for recovering parameters and data which have been observed imperfectly. The cross-entropy approach redefines the estimation problem as estimating and minimizing the divergence from the original prior while satisfying various constraints. In our application, we take mean BMI values as given and use the cross-entropy method to find the shape and position parameters of the log-normal distribution which jointly minimize the deviation of the estimates of the prevalence of overweight and the prevalence of obesity from the input parameters.

We estimated the relationship between national food availability and mean BMI by pairing FAO food availability data for the years 1980-2009 with WHO data on mean BMI for the same period. Using a polynomial trend yielded the following relationship $\left(R^{2}=0.46\right)$ :

$$
\operatorname{BMI}(r)=\left(-9.53 \cdot 10^{-7}\right) \cdot k \operatorname{cal}(r)^{2}+\left(7.87 \cdot 10^{-3}\right) \cdot k \operatorname{cal}(r)+10.18
$$

where $k c a l(r)$ denotes food availability in region $r$ in terms of kcal per person per day, and $B M I(r)$ denotes the average mean BMI in that region. Supplementary Figure 1 provides a graphical depiction. 
Supplementary Figure 1. Association between food availability and mean BMI based on data from FAO and WHO for the years 1980-2009.

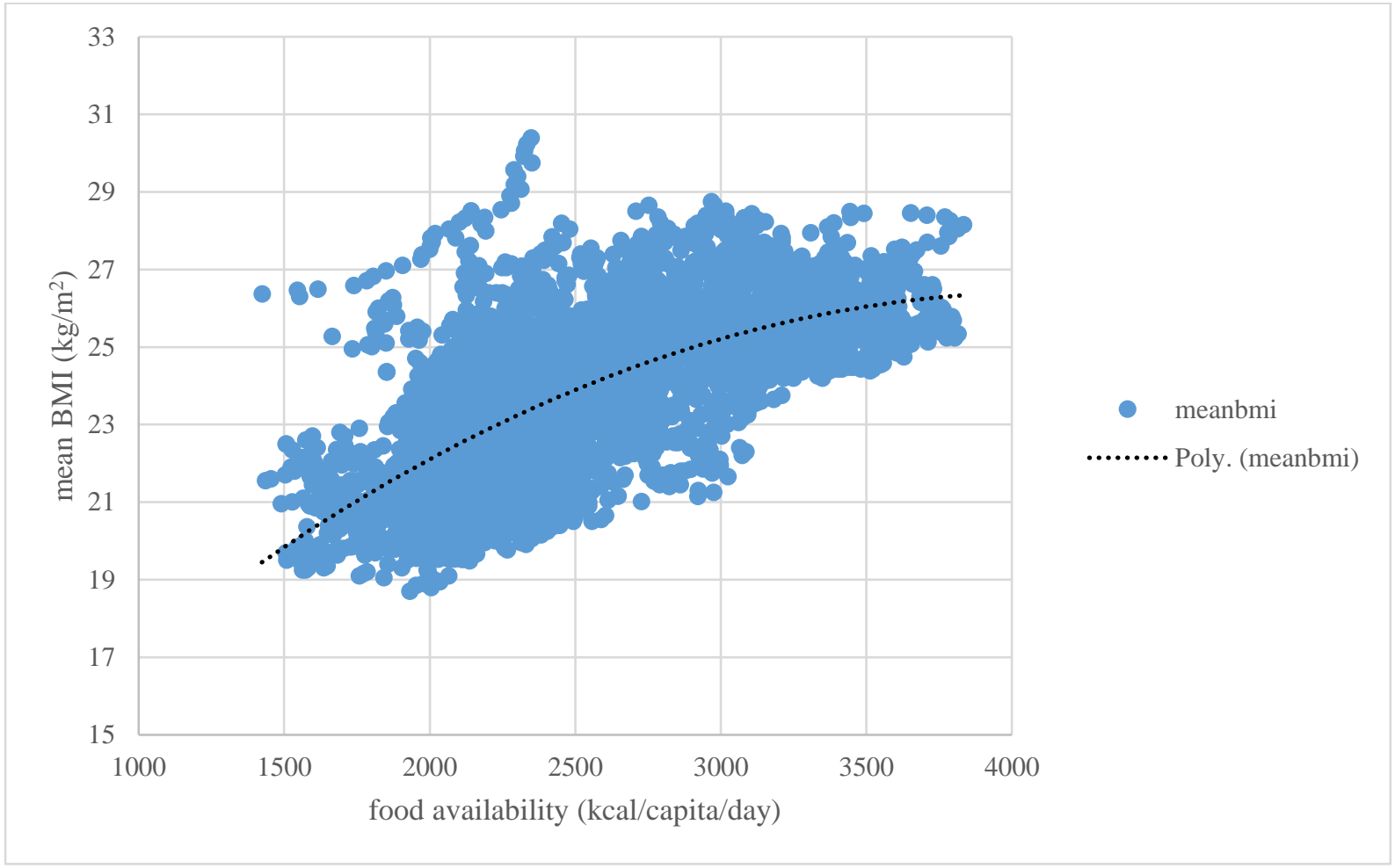

Based on the relationship between mean BMI and food availability, we estimated the changes in the weight distribution as follows. We calculated the mean BMI values for the years 2010 and 2020 using food availability projections from the tax scenarios, and we then used the percentage change in mean BMI between 2010 and 2020 to shift the baseline BMI distribution. In shifting the weight distribution, we held constant the distribution's shape parameter, $\sigma(r)$, and re-calculated its position parameter $\mu(r)$ based on the estimated mean: $\mu(r)=\log B M I(r)-\frac{\sigma(r)^{2}}{2}$. Analyses were conducted to assess the impact of holding the shape parameter constant, which showed that results were not sensitive to this assumption. 


\section{SI.3 Supplementary environmental methods}

We adopted the emissions factors for livestock from a global life cycle assessment with regional detail undertaken by the Food and Agriculture Organization (FAO) (Supplementary Table 3$)^{21}$. The assessment included all main emissions sources along the food supply chain from the farm gate to the retail point, including land use, feed production, animal production, processing, and transport, including international trade. Emissions factors for non-animal products were adopted from a comprehensive meta-analysis of life cycle assessments including 555 estimates (Supplementary Table 4) ${ }^{22}$.

Our emissions estimates for animal-based commodities for the year 2005 agree reasonably well with those by Gerber et $\mathrm{al}^{21}$ (Supplementary Table 5). The differences in emissions are less than $5 \%$ for beef, lamb, poultry, and eggs, $12 \%$ for pork, and $21 \%$ for milk. Differences in production data account for most of the differences. The Gerber et $\mathrm{al}^{21}$ estimates used FAO data, whereas we used data from the IMPACT model that whilst also based on FAO data was estimated using a cross-entropy method which allowed us to produce a consistent and balanced base year database ${ }^{1}$. Differences in regional and commodity aggregation account for the remaining differences, in particular for milk. We adopted the regional estimates from Gerber et $\mathrm{al}^{21}$ and produced new global averages based on our production data.

Supplementary Table 3. GHG emissions intensities for animal-based foods by food commodity and region ( $\mathrm{kgCO} 2$-eq per kg). Based on Gerber and colleagues ${ }^{21}$. Regions include high-income countries (HIC), upper middle-income countries (UMC), lower middle-income countries (LMC), low-income countries (LIC); and the low and middle-income countries of Africa (AFR_LMIC), America (AMR_LMIC), the Eastern Mediterranean (EMR_LMIC), Europe (EUR_LMIC), South-East Asia (SEA_LMIC), the Western Pacific (WPR_LMIC), and a global average (World).

\begin{tabular}{lrrrrrr}
\hline Region & Beef & Lamb & Pork & Poultry & Milk & Eggs \\
\hline World & 53.05 & 25.58 & 6.08 & 5.76 & 3.93 & 3.87 \\
HIC & 26.83 & 21.25 & 5.75 & 5.33 & 1.86 & 3.58 \\
UMC & 53.31 & 25.97 & 6.64 & 5.63 & 3.85 & 3.70 \\
LMC & 57.96 & 26.03 & 6.04 & 5.92 & 3.98 & 3.81 \\
LIC & 64.58 & 28.75 & 6.05 & 5.72 & 6.48 & 4.73 \\
AFR_LMIC & 71.03 & 30.98 & 6.05 & 5.40 & 8.98 & 5.93 \\
AMR_LMIC & 72.00 & 26.00 & 7.20 & 5.85 & 3.80 & 3.80 \\
EMR_LMIC & 52.50 & 28.52 & 6.05 & 6.03 & 4.84 & 3.27 \\
EUR_LMIC & 18.91 & 24.68 & 5.91 & 5.17 & 2.56 & 2.88 \\
SEA_LMIC & 70.07 & 27.77 & 6.04 & 6.16 & 4.71 & 3.36 \\
WPR_LMIC & 46.89 & 22.96 & 6.00 & 5.80 & 2.40 & 4.20 \\
\hline
\end{tabular}


Supplementary Table 4. GHG emissions intensities for plant-based foods by food commodity (kgCO2-eq per kg). Based on Tilman and Clark ${ }^{22}$.

\begin{tabular}{lc}
\hline Food item & Emissions intensity (kgCO2-eq per kg) \\
\hline Vegetable oils & 5.17 \\
Rice & 1.89 \\
Wheat & 0.65 \\
Vegetables & 0.64 \\
Other grains & 0.55 \\
Maize & 0.34 \\
Oil crops & 0.32 \\
Sugar & 0.26 \\
Fruits (tropical) & 0.26 \\
Legumes & 0.26 \\
Fruits (temperate) & 0.17 \\
Roots & 0.09 \\
\hline
\end{tabular}

Supplementary Table 5. Comparison of GHG emissions estimates between this study and FAO estimates produced by Gerber et $\mathrm{al}^{21}$.

\begin{tabular}{lrrrrrr}
\hline $\begin{array}{l}\text { Food } \\
\text { commodity }\end{array}$ & $\begin{array}{l}\text { GHG } \\
\text { emissions in } \\
\begin{array}{l}2020 \\
\text { (MtCO2-eq) }\end{array}\end{array}$ & $\begin{array}{l}\text { Productio } \\
\text { n in 2020 } \\
\text { (Mt) }\end{array}$ & $\begin{array}{l}\text { GHG } \\
\text { emissions in } \\
2005 \\
\text { (MtCO2-eq) }\end{array}$ & $\begin{array}{l}\text { Production } \\
\text { in 2005 } \\
\text { (Mt) }\end{array}$ & $\begin{array}{l}\text { FAO estimates on } \\
\text { GHG emissions in } \\
\text { 2005 (MtCO2-eq) }\end{array}$ & $\begin{array}{l}\text { FAO estimates } \\
\text { on production } \\
\text { in 2005 (Mt) }\end{array}$ \\
\hline Beef & $3,843.8$ & 83.3 & $2,754.2$ & 62.3 & $2,837.0$ & 61.4 \\
Lamb & 470.8 & 18.7 & 310.4 & 12.5 & 299.0 & 12.6 \\
Pork & 698.3 & 116.6 & 587.0 & 98.0 & 668.0 & 110.2 \\
Poultry & 594.5 & 107.7 & 406.6 & 74.5 & 389.0 & 71.6 \\
Milk & $2,364.4$ & 703.2 & $1,723.1$ & 538.6 & $1,419.0$ & 508.6 \\
Eggs & 258.8 & 67.2 & 207.8 & 54.2 & 217.0 & 58.0 \\
\hline
\end{tabular}




\section{SI.4 Supplementary health methods}

We estimated the mortality and disease burden attributable to dietary and weight-related risk factors by calculating population impact fractions (PIFs) which represent the proportions of disease cases that would be avoided when the risk exposure was changed from a baseline situation to a counterfactual situation. For calculating PIFs, we used the general formula ${ }^{23-25}$ :

$$
P I F=\frac{\int R R(x) P(x) d x-\int R R(x) P^{\prime}(x) d x}{\int R R(x) P(x) d x}
$$

where $R R(x)$ is the relative risk of disease for risk factor level $x, P(x)$ is the number of people in the population with risk factor level $x$ in the baseline scenario, and $P^{\prime}(x)$ is the number of people in the population with risk factor level $x$ in the counterfactual scenario. We assumed that changes in relative risks follow a dose-response relationship ${ }^{24}$, and that PIFs combine multiplicatively ${ }^{24,26}$, i.e. $P I F=1-\prod_{i}\left(1-P I F_{i}\right)$ where the $i$ 's denote independent risk factors.

The number of avoided deaths due to the change in risk exposure of risk $i, \Delta$ death $s_{\mathrm{i}}$, was calculated by multiplying the associated PIF by disease-specific death rates, DR, and by the number of people alive within a population, $\mathrm{P}$ :

$$
\Delta \text { deaths }_{i}(r, a, d)=P I F_{i}(r, d) \cdot D R(r, a, d) \cdot P(r, a)
$$

where PIFs are differentiated by region $r$ and disease/cause of death $d$; the death rates are differentiated by region, age group $a$, and disease; the population groups are differentiated by region and age group; and the change in the number of deaths is differentiated by region, age group and disease.

In addition to changes in mortality, we also calculated the years of life saved (YLS) and disability-adjusted life years (DALYs) saved due to a change in dietary and weight-related risk factors. For calculating YLS, we multiplied each age-specific death by the life expectancy expected at that age using the Global Burden of Disease standard abridged life table ${ }^{26}$, and for calculating DALYs, we used region and age-specific mortality-DALY ratios calculated from WHO estimates for the year 2012.

We used publically available data sources to parameterize the comparative risk analysis. Mortality data were adopted from the Global Burden of Disease project ${ }^{27}$, and projected forward by using data from the UN Population Division ${ }^{28}$. The relative risk estimates used in the calculations were adopted from pooled analyses of prospective cohort studies ${ }^{29,30}$, and from meta-analysis of prospective cohort and case-control studies ${ }^{31-38}$. The cancer associations have been judged as probable or convincing by the World Cancer Research Fund, and in each case a dose-response relationship was apparent and consistent evidence suggests plausible mechanisms ${ }^{35}$. The weight-related relative risk parameters were aggregated to the BMI categories used in this study and normalized to a risk-neutral normal weight category 
consistent with the epidemiological evidence ${ }^{29,30}$. Supplementary Table 6 lists the relative risk parameters adopted in this study. The selection procedure is detailed below.

In sensitivity analyses, we estimated the health impacts on children using different models. For analysing the weight-related health burden for children (aged 5 and younger), we include two separate risk factors in our comparative risk assessment, moderate and severe stunting. Children are considered moderately stunted if they are more than two standard deviations below the expected mean ratio of height-for-age, and severely stunted if they are three standard deviations below that ratio. We estimated the prevalence of moderate and severe stunting using a model that resolves the food and non-food (socio-economic) causes of stunting $^{39}$. As proxy for food-related causes, we used IMPACT-based estimates of the percentage of undernourished children which are based on a relationship of per capita calorie consumption, female access to secondary education, the quality of maternal and child care, and health and sanitation ${ }^{40}$; and as proxy for non-food causes of stunting, we followed Lloyd and colleagues in constructing a development score based on projections of GDP per capita and current Gini coefficients ${ }^{39}$.

Supplementary Table 6. Relative risk parameters (mean and 95\% confidence intervals in parenthesis) for coronary heart disease (CHD), stroke, cancer, type 2 diabetes mellitus (T2DM), and an aggregate of other causes of death (other).

\begin{tabular}{|c|c|c|c|c|c|}
\hline \multirow{2}{*}{ Risk factor } & \multicolumn{5}{|c|}{ Relative risk per cause of death } \\
\hline & $\mathrm{CHD}$ & Stroke & Cancer & T2DM & Other \\
\hline Fruit and vegetable consumption & $0.96(0.93-0.99)$ & $0.95(0.92-0.97)$ & $0.93(0.84-0.99)^{*}$ & $0.96(0.92-0.99)$ & 1 \\
\hline Red meat consumption & $1.25(1.21-1.29)$ & $1.10(1.05-1.15)$ & $1.01(1.00-1.05)^{*}$ & $1.15(1.07-1.24)$ & 1 \\
\hline underweight & $0.67(0.65-0.70)$ & $1.03(0.71-1.47)$ & $1.11(0.94-1.32)$ & 1 & $1.75(1.50-2.05)$ \\
\hline normal weight & 1 & 1 & 1 & 1 & 1 \\
\hline overweight & $1.31(1.24-1.39)$ & $1.07(0.73-1.59)$ & $1.10(1.04-1.17)$ & $1.54(1.42-1.68)$ & $0.96(0.89-1.03)$ \\
\hline obese & $1.78(1.64-1.92)$ & $1.55(1.14-2.11)$ & $1.40(1.30-1.50)$ & $7.37(5.16-10.47)$ & $1.33(1.22-1.46)$ \\
\hline moderate stunting & 1 & 1 & 1 & 1 & $1.6(1.3-2.2)$ \\
\hline severe stunting & 1 & 1 & 1 & 1 & $4.1(2.6-6.4)$ \\
\hline
\end{tabular}

* global average, actual relative risk is region-specific.

Sources: Dauchet et al (2005, 2006), Micha et al (2010), Chen et al (2013), WCRI/AIC (2007), Li et al (2014), Feskens et al (2013), Prospective Studies Collaboration (2009), Berrington de Gonzales et al (2010), Black et al (2008). 


\section{Weight-related risk parameters}

Excess weight is an established risk factor for several causes of death, including ischaemic heart disease $\mathrm{e}^{41,42}$, stroke $^{42-44}$, and various cancers ${ }^{35,45-47}$. Plausible biological explanations $\mathrm{s}^{30,48,49}$ and the identification of mediating factors ${ }^{30,50}$ suggest that the association between body weight and mortality is not merely statistical association, but a causal link independent of other factors, such as diet and exercise ${ }^{51-55}$.

We inferred the parameters describing relative mortality risk due to weight categories from two large, pooled analyses of prospective cohort studies ${ }^{29,30}$. We concentrated on four causes of death: ischaemic/coronary heart disease (CHD), stroke, cancers, and type-2 diabetes mellitus (T2DM). We adopted the relative risks for CHD, stroke, and T2DM from the Prospective Studies Collaboration ${ }^{30}$, which analysed the association between BMI and mortality among 900,000 persons in 57 prospective studies that were primarily designed to evaluate risk factors for cardiovascular disease; and we adopted the relative risks for cancer from Berrington de Gonzalez and colleagues ${ }^{29}$ who examined the relationship between BMI and mortality in a pooled analysis of 19 prospective studies which included 1.46 million adults and which were predominantly designed to study cancer.

From each study, we adopted the relative risk rates for lifelong non-smokers to minimize confounding and reverse causality, and, to increase comparability, we normalized the relativerisk schedule to the lowest risk which, in each case corresponded to a body-mass index (BMI) of 22.5-25. We then used the number of cause-specific deaths to aggregate the BMI intervals of 2.5 that have been used in the studies to the WHO classification of BMI ranges.

\section{Dietary risk parameters}

Dietary risks have been the leading risk factors for death globally in $2010^{24}$. The Global Burden of Disease Study included 14 different components as dietary risks, such as not eating enough fruit, nuts and seeds, vegetables, whole grains, and omega-3s and eating too much salt and processed meat ${ }^{24}$. In this study, we focused on changes in the consumption of fruits, vegetables, and red meat. Those categories constituted about two thirds of the total dietary risk in 2010 (excluding potential double counting, e.g. of fibre found in vegetables and sodium found in processed meat) ${ }^{24}$, and country-level trends and data are available for most countries worldwide. We adopted relative-risk parameters for developing specific diseases from recent meta-analyses of existing studies. In each case, the association between risk factors and disease outcome was linear, suggesting a dose-response relationship across the range of consumption levels that were analysed.

\section{Meat consumption and cardiovascular disease}

The relative risks of coronary heart diseases due to meat consumption were adopted from Micha and colleagues ${ }^{31}$. Their comprehensive systematic review and meta-analysis of the relationship between meat consumption (processed, red, and total meat) and cardiovascular 
diseases (coronary heart disease (CHD), type-2 diabetes mellitus (T2DM), and stroke) included 20 studies (17 prospective cohorts and 3 case-control studies) with 1,218,380 individuals from 10 countries. However, analyses of specific subcategories, e.g. total meat consumption and stroke, included significantly less studies. The results show positive associations between consumption of processed and total meat and the incidence of CHD, diabetes mellitus, and stroke. Since the publication of Micha et $\mathrm{al}^{31}$, updated reviews of the association between meat consumption and stroke have become available. We therefore only adopted the estimates for the association between meat consumption and coronary heart disease from the Micha et al study. We adopted the findings for total meat indicating that consumption of $100 \mathrm{~g}$ per day increases CHD risk by $25 \%$ ( $\mathrm{RR}=1.25 ; 95 \% \mathrm{CI}, 1.21$ to 1.29 ). The estimate is based on data from 4 prospective cohort studies; one extremely positive finding from a case-control study was excluded in the estimate ${ }^{31}$.

The relative risk of stroke due to meat consumption was adopted from Chen et al ${ }^{32}$ which, for stroke, provided an updated meta-analysis of Micha et $\mathrm{al}^{31}$ containing five large independent cohort studies (compared to two in Micha et $\mathrm{al}^{31}$ ). Chen et $\mathrm{al}^{32}$ found that consumption of red and/or processed meat increases the risk of stroke, in particular, ischemic stroke. Their doseresponse analysis of the primary studies showed that the risk of stroke increased significantly by $10 \%$ for each $100 \mathrm{~g}$ per day increment in total meat consumption $(\mathrm{RR}=1.10 ; 95 \% \mathrm{CI}$, $1.05-1.15)$, by $13 \%$ for each $100 \mathrm{~g}$ per day increment in red meat consumption ( $\mathrm{RR}=1.13$; 95\% CI, 1.03-1.23) and by $11 \%$ for each $50 \mathrm{~g}$ per day increment in processed meat consumption ( $\mathrm{RR}=1.11 ; 95 \% \mathrm{CI}, 1.02-1.20)$, with low study heterogeneity. We adopted the estimate for total meat consumption.

\section{Meat consumption and diabetes}

The relative risk of T2DM due to meat consumption was adopted Feskens et al ${ }^{37}$ who updates the meta-analysis of Micha et $\mathrm{al}^{31}$ for T2DM. For total meat consumption, Feskens et $\mathrm{al}^{37}$ included findings from 14 separate cohorts result, resulting in a pooled RR of 1.15 per $100 \mathrm{~g}$ ( $\mathrm{RR}=1.15 ; 95 \% \mathrm{CI}, 1.07-1.24)$, indicating that for each $100 \mathrm{~g}$ of total meat consumed, the risk of T2DM increases by $15 \%$. For red meat, the overall RR based on 14 individual studies was 1.13 per $100 \mathrm{~g}$ (95\% CI, 1.03-1.23), and for processed meat, the summary estimate of 21 separate cohorts was 1.32 per $50 \mathrm{~g}$ (95\% CI, 1.19-1.48). We adopt the total meat estimate which includes red and processed red meat.

\section{Meat consumption and cancer}

The association between meat consumption and cancer was reviewed in the Second Expert Report "Food, Nutrition, Physical Activity, and the Prevention of Cancer: a Global Perspective" published in 2007 by the World Cancer Research Fund together with the American Institute for Cancer Research ${ }^{35}$. The report is based on reviews and meta-analysis of over 7,000 scientific studies published on cancer prevention. It was the outcome of a 5-year project which involved a panel of 21 leading scientists and 9 research centres around the world. 
With respect to meat, the report concluded that ${ }^{35}$ : red and processed meats are convincing causes of colorectal cancer; there is substantial amount of evidence, with a dose-response relationship apparent from case-control studies (red meat) and cohort studies (processed meat); there is evidence (red meat) and strong evidence (processed meat) for plausible mechanisms operating in humans. The report also noted that there is limited evidence suggesting that red meat is a cause of cancers of the oesophagus, lung, pancreas and endometrium; and that processed meat is a cause of cancers of the oesophagus, lung, stomach and prostate.

We followed the conclusions of the expert report and its updates that highlighted a convincing causal link between meat consumption and colorectal cancer and adopted the following estimate: consumption of $100 \mathrm{~g} /$ day of red and processed meat increases the risk of colorectal cancer by $16 \%(\mathrm{RR}=1.16 ; 95 \% \mathrm{CI}, 1.04-1.30)$. We aggregated the estimate to region-specific relative risks for all cancers by weighing it by the ratio of regional deaths due to colorectal cancer to all cancer deaths in that region. Globally, this resulted in a relative risk of cancer of $\mathrm{RR}=1.01$.

\section{Fruit and vegetable consumption and cardiovascular disease}

The relative risks of stroke and CHD due to fruit and vegetable consumption were adopted from Dauchet and colleagues ${ }^{33,34}$. Dauchet et $\mathrm{al}^{34}$ conducted a meta-analysis for CHD and its association with fruit and vegetable consumption. The analysis included nine prospective cohort studies that consisted of 91,379 men, 129,701 women, and 5,007 CHD events. Pooled relative risks showed that $\mathrm{CHD}$ was decreased by $4 \%(\mathrm{RR}=0.96$; 95\% $\mathrm{CI}, 0.93-0.99)$ for each additional portion of $106 \mathrm{~g}$ per day of fruit and vegetable intake and by $7 \%(\mathrm{RR}=0.93 ; 95 \%$ CI, 0.89-0.96) for fruit intake. We adopted the estimate for the aggregate of fruit and vegetable consumption, i.e. $\mathrm{RR}=0.96$ (0.93-0.99).

Dauchet et $\mathrm{al}^{33}$ undertook a similar meta-analysis for stroke. The analysis included seven cohort studies with 90,513 men, 141,536 women, and 2,955 strokes. Pooled relative risks showed that the risk of stroke was decreased by $11 \%(\mathrm{RR}=0.89 ; 95 \% \mathrm{CI}, 0.85-0.93)$ for each additional portion of $106 \mathrm{~g}$ per day of fruit, by $5 \%(\mathrm{RR}=0.95 ; 95 \% \mathrm{CI}, 0.92-0.97)$ for fruit and vegetables, and by $3 \%(\mathrm{RR}=0.97 ; 95 \% \mathrm{CI}, 0.92-1.02)$ for vegetables. The study found that the association between fruit or fruit and vegetables and stroke was linear, suggesting a doseresponse relationship. We adopted the estimate for the aggregate of fruit and vegetable consumption, i.e. $\mathrm{RR}=0.95$ (0.92-0.97).

\section{Fruit and vegetable consumption and diabetes}

The relative risk of diabetes due to fruit and vegetable consumption was adopted from $\mathrm{Li}$ et $\mathrm{al}^{38}$. In their meta-analysis, Li et $\mathrm{al}^{38}$ included 10 prospective cohort studies. Eleven comparisons from nine studies reported an association between fruit intake and risk of T2DM, with 22,995 T2DM outcomes and 424,677 participants. Overall, fruit intake was inversely 
associated with risk ( $\mathrm{RR}=0.93 ; 95 \% \mathrm{CI}, 0.88-0.99)$. Dose-response analysis indicated that a 1 serving/day $(106 \mathrm{~g} / \mathrm{d})$ increment of fruit intake was associated with a $6 \%$ lower risk of T2DM ( $\mathrm{RR}=0.94 ; 95 \% \mathrm{CI}, 0.89-1.00)$. Seven comparisons from six studies reported an association between green leafy vegetables (GLV) intake and risk of T2DM, with 19,139 T2DM outcomes and 251,235 participants. Overall, GLV intake was inversely associated with risk $(\mathrm{RR}=0.87 ; 95 \% \mathrm{CI}, 0.81-0.93)$. Dose-response analysis indicated that a 0.2 serving/day $(0.2 \mathrm{x}$ $106 \mathrm{~g} / \mathrm{d})$ increment of GLV intake was associated with a $13 \%$ lower risk of T2DM $(\mathrm{RR}=0.87$; 95\% CI, 0.76-0.99). We weighted the GLV-related RR per 0.2 servings with a risk neutral RR per 0.8 servings of other vegetables, and with the fruit-related RR. This yielded a RR of 0.96 (0.92-0.99).

\section{Fruit and vegetable consumption and cancer}

The relative risks of various cancers due to fruit and vegetable consumption were adopted from the 2007 expert report of the World Cancer Research Fund and the American Institute for Cancer Research ${ }^{35}$. The export report concluded that:

"[N]on-starchy vegetables and also fruits probably protect against cancers of the mouth, larynx, pharynx, oesophagus, and stomach, and that fruits also probably protect against lung cancer. The case that vegetables, fruits, and pulses (legumes) may be protective against cancers of some sites is supported by evidence on foods containing micronutrients found in these and other plant foods. Foods containing carotenoids probably protect against cancers of the mouth, pharynx, larynx, and lung; foods containing beta-carotene and also vitamin $\mathrm{C}$ probably protect against oesophageal cancer; foods containing selenium and also lycopene probably protect against prostate cancer; and foods containing folate probably protect against pancreatic cancer. [..] [It was also found that] foods containing dietary fibre, found in plant foods (particularly when in whole or relatively unprocessed forms), probably protect against colorectal cancer."

We adopted the following relative risk parameters for which the expert report indicated a substantial amount of consistent evidence for plausible mechanisms and a dose-response relationship:

Cancers of the mouth, pharynx, and larynx:

- Consumption of non-starchy vegetables reduces the risk of cancers of the mouth, pharynx, and larynx by $28 \%$ per $50-\mathrm{g}$ serving per day (RR=0.72; 95\% CI, 0.63-0.82).

- Consumption of fruits reduces the risk of cancers of the mouth, pharynx, and larynx by $28 \%$ per $100 \mathrm{~g}$ serving per day $(\mathrm{RR}=0.72 ; 95 \% \mathrm{CI}, 0.59-0.87)$.

- We adopted the simple average of vegetable and fruit consumption for the relative risk of cancers of the mouth, pharynx, and larynx, i.e. $R R=0.72(0.61-0.85)$.

Oesophageal cancer:

- Consumption of raw vegetables reduces the risk of oesophageal cancer by $31 \%$ per 50 g serving per day $(\mathrm{RR}=0.69 ; 95 \% \mathrm{CI}, 0.58-0.83)$.

- $\quad$ Consumption of fruits reduces the risk of oesophageal cancer by $44 \%$ per $100 \mathrm{~g}$ serving per day $(\mathrm{RR}=0.56$; 95\% CI, 0.42-0.74). 
- We adopted the simple average of vegetable and fruit consumption for the relative risk of oesophageal cancer, i.e. $\mathrm{RR}=0.63(0.50-0.79)$.

Stomach cancer:

- $\quad$ Consumption of non-starchy vegetables reduces the risk of stomach cancer by $30 \%$ per $100 \mathrm{~g}$ serving per day $(\mathrm{RR}=0.70 ; 95 \% \mathrm{CI}, 0.62-0.79)$.

[Estimates of green-yellow vegetables yield $\mathrm{RR}=0.59(0.46-0.75)$ per $100 \mathrm{~g} / \mathrm{d}$; green, leafy vegetables yield $R R=0.43(0.24-0.77)$ per $50 \mathrm{~g} / \mathrm{d}$; and raw vegetables yield $\mathrm{RR}=0.5(0.38-0.65)$ per $100 \mathrm{~g} / \mathrm{d}]$

- $\quad$ Consumption of fruits reduces the risk of stomach cancer by $33 \%$ per $100 \mathrm{~g}$ serving per day (RR=0.67; 95\% CI: 0.59-0.76).

- We adopted the simple average of vegetable and fruit consumption for the relative risk of stomach cancer, i.e. $\mathrm{RR}=0.69$.

Lung cancer:

Consumption of fruits reduces the risk of lung cancer by $6 \%$ per $80 \mathrm{~g}$ serving per day ( $\mathrm{RR}=0.94 ; 95 \% \mathrm{CI}, 0.90-0.97$ ).

- We adopted the simple average of vegetable and fruit consumption for the relative risk of lung cancer (assuming no effect of vegetable consumption, $R R=1$ ), i.e. $R R=0.97$.

Overall relative risk:

We aggregated the cause-specific relative-risk estimates to region-specific all-cancer estimates by weighing each risk by the ratio of regional deaths due to the specific cancer divided by all cancer deaths in that region. Globally, this yielded an aggregate all-cancer risk of $\mathrm{RR}=0.93$. 


\section{SI.5 Supplementary results}

Supplementary Table 7. GHG taxes (USD/100g) by food commodity and region. Regions include high-income countries (HIC), upper middle-income countries (UMC), lower middle-income countries (LMC), low-income countries (LIC); and the low and middle-income countries of Africa (AFR_LMIC), America (AMR_LMIC), the Eastern Mediterranean (EMR_LMIC), Europe (EUR_LMIC), South-East Asia (SEA_LMIC), and the Western Pacific (WPR_LMIC),

\begin{tabular}{|c|c|c|c|c|c|c|c|c|c|c|c|}
\hline Food commodities & World & HIC & UMC & LMC & LIC & AFR_LMIC & AMR_LMIC & EMR_LMIC & EUR_LMIC & SEA_LMIC & WPR_LMIC \\
\hline Beef & 0.281 & 0.139 & 0.283 & 0.305 & 0.338 & 0.368 & 0.374 & 0.267 & 0.101 & 0.365 & 0.243 \\
\hline Lamb & 0.134 & 0.111 & 0.135 & 0.136 & 0.150 & 0.161 & 0.135 & 0.148 & 0.129 & 0.144 & 0.119 \\
\hline Pork & 0.030 & 0.028 & 0.035 & 0.030 & 0.030 & 0.031 & 0.037 & 0.022 & 0.031 & 0.031 & 0.031 \\
\hline Poultry & 0.030 & 0.028 & 0.029 & 0.031 & 0.030 & 0.028 & 0.030 & 0.031 & 0.027 & 0.032 & 0.030 \\
\hline Oils & 0.027 & 0.027 & 0.027 & 0.027 & 0.027 & 0.027 & 0.027 & 0.027 & 0.027 & 0.027 & 0.027 \\
\hline Milk & 0.021 & 0.010 & 0.020 & 0.021 & 0.035 & 0.047 & 0.020 & 0.025 & 0.014 & 0.025 & 0.012 \\
\hline Eggs & 0.020 & 0.018 & 0.019 & 0.020 & 0.025 & 0.031 & 0.020 & 0.017 & 0.015 & 0.017 & 0.022 \\
\hline Rice & 0.010 & 0.010 & 0.010 & 0.010 & 0.010 & 0.010 & 0.010 & 0.010 & 0.010 & 0.010 & 0.010 \\
\hline Wheat & 0.003 & 0.003 & 0.003 & 0.003 & 0.003 & 0.003 & 0.003 & 0.003 & 0.003 & 0.003 & 0.003 \\
\hline Vegetables & 0.003 & 0.003 & 0.003 & 0.003 & 0.003 & 0.003 & 0.003 & 0.003 & 0.003 & 0.003 & 0.003 \\
\hline Other grains & 0.003 & 0.003 & 0.003 & 0.003 & 0.003 & 0.003 & 0.003 & 0.003 & 0.003 & 0.003 & 0.003 \\
\hline Maize & 0.002 & 0.002 & 0.002 & 0.002 & 0.002 & 0.002 & 0.002 & 0.002 & 0.002 & 0.002 & 0.002 \\
\hline Oil crops & 0.002 & 0.002 & 0.002 & 0.002 & 0.002 & 0.002 & 0.002 & 0.002 & 0.002 & 0.002 & 0.002 \\
\hline Sugar & 0.001 & 0.001 & 0.001 & 0.001 & 0.001 & 0.001 & 0.001 & 0.001 & 0.001 & 0.001 & 0.001 \\
\hline Legumes & 0.001 & 0.001 & 0.001 & 0.001 & 0.001 & 0.001 & 0.001 & 0.001 & 0.001 & 0.001 & 0.001 \\
\hline Fruits (trop.) & 0.001 & 0.001 & 0.001 & 0.001 & 0.001 & 0.001 & 0.001 & 0.001 & 0.001 & 0.001 & 0.001 \\
\hline Fruits (temp.) & 0.001 & 0.001 & 0.001 & 0.001 & 0.001 & 0.001 & 0.001 & 0.001 & 0.001 & 0.001 & 0.001 \\
\hline Roots & 0.000 & 0.000 & 0.000 & 0.000 & 0.000 & 0.000 & 0.000 & 0.000 & 0.000 & 0.000 & 0.000 \\
\hline
\end{tabular}


Supplementary Table 8. Percentage change in food prices by commodity and region. Regions include high-income countries (HIC), upper middle-income countries (UMC), lower middle-income countries (LMC), low-income countries (LIC); and the low and middle-income countries of Africa (AFR_LMIC), America (AMR_LMIC), the Eastern Mediterranean (EMR_LMIC), Europe (EUR_LMIC), South-East Asia (SEA_LMIC), and the Western Pacific (WPR_LMIC).

\begin{tabular}{|c|c|c|c|c|c|c|c|c|c|c|c|}
\hline Food commodities & World & $\mathrm{HIC}$ & UMC & LMC & LIC & AFR_LMIC & AMR_LMIC & EMR_LMIC & EUR_LMIC & SEA_LMIC & WPR_LMIC \\
\hline Beef & 40.3 & 26.6 & 44.7 & 42.8 & 41.0 & 42.3 & 60.1 & 29.2 & 12.5 & 48.4 & 42.6 \\
\hline Oils & 25.3 & 34.7 & 27.0 & 23.3 & 21.3 & 20.2 & 29.0 & 20.2 & 21.9 & 17.6 & 32.4 \\
\hline Milk & 21.0 & 13.4 & 21.9 & 20.8 & 29.4 & 39.1 & 22.2 & 20.5 & 12.2 & 23.5 & 15.1 \\
\hline Lamb & 14.9 & 16.3 & 15.5 & 14.6 & 13.8 & 14.0 & 16.5 & 12.5 & 12.0 & 14.6 & 15.8 \\
\hline Poultry & 8.5 & 10.7 & 8.5 & 8.3 & 6.6 & 6.0 & 9.3 & 6.6 & 6.5 & 8.2 & 9.6 \\
\hline Other grains & 8.2 & 12.6 & 9.8 & 7.2 & 6.1 & 6.2 & 10.6 & 6.0 & 7.7 & 5.4 & 9.9 \\
\hline Rice & 8.2 & 10.1 & 9.0 & 7.8 & 6.7 & 6.0 & 9.7 & 6.6 & 6.8 & 6.4 & 10.6 \\
\hline Wheat & 7.7 & 9.6 & 7.8 & 7.6 & 6.1 & 6.0 & 8.3 & 5.4 & 6.2 & 7.1 & 9.1 \\
\hline Pork & 6.8 & 8.3 & 7.8 & 6.6 & 5.4 & 5.3 & 8.9 & 3.9 & 5.7 & 6.2 & 8.1 \\
\hline Maize & 5.9 & 7.4 & 6.1 & 5.7 & 5.0 & 4.7 & 6.5 & 4.2 & 5.0 & 5.1 & 7.3 \\
\hline Eggs & 5.3 & 6.6 & 5.3 & 5.0 & 5.1 & 6.1 & 5.6 & 3.3 & 3.4 & 4.1 & 6.4 \\
\hline Oil crops & 2.1 & 2.5 & 2.2 & 2.0 & 1.8 & 1.7 & 2.3 & 1.7 & 1.6 & 1.7 & 2.8 \\
\hline Vegetables & 1.9 & 3.0 & 2.1 & 1.6 & 1.4 & 1.3 & 2.2 & 1.4 & 1.9 & 1.5 & 2.1 \\
\hline Sugar & 1.7 & 2.2 & 2.2 & 1.4 & 1.9 & 2.0 & 2.4 & 1.0 & 1.8 & 1.4 & 1.6 \\
\hline Legumes & 0.9 & 1.2 & 0.8 & 0.9 & 0.8 & 0.7 & 0.7 & 0.8 & 1.0 & 0.7 & 1.2 \\
\hline Roots & 0.9 & 1.1 & 1.1 & 0.8 & 0.8 & 0.8 & 1.3 & 0.6 & 0.6 & 0.9 & 0.8 \\
\hline Fruits (trop.) & 0.8 & 1.2 & 0.9 & 0.7 & 0.7 & 0.6 & 1.0 & 0.5 & 0.8 & 0.7 & 0.8 \\
\hline Fruits (temp.) & 0.4 & 0.6 & 0.4 & 0.4 & 0.3 & 0.3 & 0.5 & 0.3 & 0.4 & 0.3 & 0.5 \\
\hline
\end{tabular}


Supplementary text on changes in food consumption: In absolute terms (Supplementary Table 10), average red meat consumption per person was reduced by $5 \mathrm{~g} \mathrm{~d}^{-1}(7 \%)$, ranging from $2 \mathrm{~g} \mathrm{~d}^{-1}(13 \%)$ in the LMICs of South-East Asia to $16 \mathrm{~g} \mathrm{~d}^{-1}(16 \%)$ in the LMICs of the Americas. Fruit and vegetable consumption per person was reduced by $3 \mathrm{~g} \mathrm{~d}^{-1}(0.8 \%)$ on average, ranging from $2 \mathrm{~g} \mathrm{~d}^{-1}$ in high-income countries $(0.6 \%)$ and the LMICs of Europe $(0.7 \%)$ to $5 \mathrm{~g} \mathrm{~d}^{-1}(0.8 \%)$ in the LMICs of the Western Pacific. Average total energy consumption (Supplementary Table 11) decreased by $84 \mathrm{kcal} \mathrm{d}^{-1}(3 \%)$ per person, ranging from $48 \mathrm{kcal} \mathrm{d}^{-1}(1.6 \%)$ in the LMICs of Europe to $102 \mathrm{kcal} \mathrm{d}^{-1}(3.6 \%)$ and $105 \mathrm{kcal} \mathrm{d}^{-1}(3.3 \%)$ in the LMICs of the Americas and the Western Pacific, respectively. Limiting the tax coverage by excluding health-critical food groups, taxing only animal-based commodities or focusing on red meat, led to smaller reductions in energy consumption (41-92\% less) and fruit and vegetable consumption (72-90\% less) (Supplementary Table 12). Fewer reductions, in particular in fruit and vegetable consumption, were achieved when, in addition to limiting the tax coverage, tax revenues were used to compensate income losses; and as one would expect, more fruits and vegetable were consumed (7-22\% more) in tax scenarios that used part of the tax revenues to subsidise this food type. 
Supplementary Table 9. Percentage change in per-capita food consumption (net of waste) by commodity and region. Regions include high-income countries (HIC), upper middle-income countries (UMC), lower middle-income countries (LMC), low-income countries (LIC); and the low and middle-income countries of Africa (AFR_LMIC), America (AMR_LMIC), the Eastern Mediterranean (EMR_LMIC), Europe (EUR_LMIC), South-East Asia (SEA_LMIC), and the Western Pacific (WPR_LMIC).

\begin{tabular}{|c|c|c|c|c|c|c|c|c|c|c|c|}
\hline Food commodities & World & $\mathrm{HIC}$ & UMC & LMC & LIC & AFR_LMIC & AMR_LMIC & EMR_LMIC & EUR_LMIC & SEA_LMIC & WPR_LMIC \\
\hline Beef & -13.3 & -6.9 & -17.5 & -15.0 & -19.3 & -22.0 & -21.7 & -10.8 & -3.0 & -21.3 & -13.8 \\
\hline Oils & -8.5 & -11.3 & -7.5 & -7.6 & -7.7 & -6.9 & -8.7 & -5.8 & -5.3 & -5.7 & -10.9 \\
\hline Milk & -7.5 & -1.8 & -6.4 & -11.6 & -13.3 & -17.7 & -6.7 & -10.7 & -3.0 & -15.2 & -8.5 \\
\hline Lamb & -5.6 & -3.9 & -6.3 & -5.2 & -8.6 & -7.9 & -7.2 & -6.0 & -5.4 & -7.6 & -4.2 \\
\hline Wheat & -2.8 & -2.3 & -2.1 & -3.1 & -3.5 & -3.4 & -2.3 & -1.9 & -1.7 & -3.1 & -4.3 \\
\hline Rice & -2.7 & -1.8 & -3.2 & -2.7 & -3.0 & -4.0 & -3.2 & -2.6 & -2.3 & -2.2 & -3.3 \\
\hline Other grains & -2.1 & -2.3 & -1.8 & -1.8 & -2.6 & -2.4 & -2.7 & -1.5 & -0.7 & -1.6 & -1.7 \\
\hline Maize & -2.0 & -1.6 & -1.8 & -1.9 & -2.5 & -2.4 & -1.8 & -1.0 & -0.5 & -2.3 & -1.5 \\
\hline Poultry & -1.9 & -1.1 & -1.9 & -2.6 & -2.2 & -1.9 & -2.4 & -1.7 & -1.1 & -1.5 & -3.1 \\
\hline Pork & -1.5 & -2.3 & -2.8 & -0.9 & -1.3 & -2.6 & -3.9 & 0.0 & -1.5 & -1.0 & -0.8 \\
\hline Eggs & -1.3 & -1.2 & -0.6 & -1.5 & -2.1 & -1.7 & -1.0 & -0.8 & 0.1 & -1.4 & -1.6 \\
\hline Vegetables & -1.0 & -0.9 & -0.9 & -0.9 & -1.6 & -1.3 & -1.3 & -0.8 & -0.7 & -1.3 & -0.9 \\
\hline Sugar & -0.8 & -0.5 & -0.8 & -0.9 & -1.4 & -1.2 & -0.9 & -1.1 & -0.7 & -0.9 & -0.8 \\
\hline Oil crops & -0.6 & -0.7 & -1.1 & -0.4 & -1.0 & -0.9 & -1.2 & -1.0 & -0.7 & -0.6 & -0.2 \\
\hline Fruits (trop.) & -0.5 & -0.3 & -0.4 & -0.5 & -1.1 & -0.8 & -0.4 & -0.8 & -0.3 & -0.6 & -0.4 \\
\hline Legumes & -0.4 & -0.1 & -0.2 & -0.3 & -0.9 & -0.8 & -0.2 & -0.4 & -0.1 & -0.3 & -0.1 \\
\hline Fruits (temp.) & -0.3 & 0.0 & -0.2 & -0.4 & -1.0 & -0.6 & -0.3 & -0.4 & -0.1 & -0.8 & -0.3 \\
\hline Roots & -0.3 & -0.1 & -0.1 & -0.2 & -0.6 & -0.4 & -0.2 & -0.5 & -0.1 & -0.5 & -0.1 \\
\hline Other crops & -0.2 & -0.1 & -0.2 & -0.2 & -0.7 & -0.5 & -0.2 & -0.4 & -0.1 & -0.2 & -0.1 \\
\hline All commodities & -2.8 & -1.8 & -3.1 & -3.0 & -3.3 & -3.1 & -3.7 & -3.7 & -1.5 & -4.0 & -2.3 \\
\hline Fruit \&vegetables & -0.8 & -0.6 & -0.6 & -0.8 & -1.3 & -1.0 & -0.7 & -0.7 & -0.5 & -1.1 & -0.8 \\
\hline Red meat & -6.4 & -4.3 & -12.4 & -5.0 & -11.0 & -15.3 & -16.5 & -9.2 & -2.7 & -12.5 & -3.3 \\
\hline
\end{tabular}


Supplementary Table 10. Absolute change in per-capita food consumption (g/d) (net of waste) by commodity and region. Regions include high-income countries (HIC), upper middle-income countries (UMC), lower middle-income countries (LMC), low-income countries (LIC); and the low and middle-income countries of Africa (AFR_LMIC), America (AMR_LMIC), the Eastern Mediterranean (EMR_LMIC), Europe (EUR_LMIC), South-East Asia (SEA_LMIC), and the Western Pacific (WPR_LMIC).

\begin{tabular}{|c|c|c|c|c|c|c|c|c|c|c|c|}
\hline Food commodities & World & $\mathrm{HIC}$ & UMC & LMC & LIC & AFR_LMIC & AMR_LMIC & EMR_LMIC & EUR_LMIC & SEA_LMIC & WPR_LMIC \\
\hline Milk & -18.18 & -9.39 & -21.52 & -21.33 & -11.92 & -15.24 & -20.45 & -29.67 & -12.26 & -26.72 & -11.72 \\
\hline Beef & -3.72 & -4.18 & -9.74 & -2.32 & -3.19 & -3.94 & -14.69 & -2.37 & -1.07 & -1.46 & -2.99 \\
\hline Wheat & -3.47 & -3.20 & -3.29 & -3.86 & -2.35 & -2.32 & -2.28 & -4.46 & -4.00 & -3.06 & -4.73 \\
\hline Rice & -3.41 & -0.59 & -1.58 & -4.17 & -5.13 & -2.46 & -2.10 & -1.19 & -0.28 & -5.13 & -5.99 \\
\hline Oils & -2.60 & -5.60 & -2.75 & -2.06 & -1.39 & -1.80 & -3.02 & -1.48 & -1.83 & -1.32 & -3.00 \\
\hline Vegetables & -2.53 & -1.97 & -1.59 & -3.15 & -1.59 & -1.31 & -1.48 & -1.74 & -2.00 & -2.26 & -4.81 \\
\hline Maize & -0.71 & -0.26 & -1.29 & -0.46 & -1.63 & -2.37 & -1.75 & -0.29 & -0.08 & -0.53 & -0.20 \\
\hline Poultry & -0.70 & -0.88 & -1.30 & -0.62 & -0.24 & -0.24 & -1.75 & -0.37 & -0.46 & -0.19 & -1.22 \\
\hline Pork & -0.58 & -1.73 & -0.74 & -0.34 & -0.17 & -0.14 & -1.02 & 0.00 & -0.42 & -0.04 & -0.80 \\
\hline Sugar & -0.54 & -0.46 & -0.92 & -0.51 & -0.39 & -0.44 & -1.06 & -0.86 & -0.70 & -0.54 & -0.27 \\
\hline Fruits (trop.) & -0.54 & -0.32 & -0.52 & -0.50 & -0.94 & -0.97 & -0.78 & -0.68 & -0.13 & -0.57 & -0.34 \\
\hline Other grains & -0.49 & -0.24 & -0.20 & -0.41 & -1.35 & -2.31 & -0.20 & -0.42 & -0.10 & -0.34 & -0.06 \\
\hline Roots & -0.37 & -0.07 & -0.18 & -0.33 & -1.05 & -1.40 & -0.17 & -0.26 & -0.12 & -0.40 & -0.14 \\
\hline Lamb & -0.35 & -0.21 & -0.31 & -0.37 & -0.46 & -0.58 & -0.16 & -0.69 & -0.44 & -0.19 & -0.42 \\
\hline Eggs & -0.30 & -0.37 & -0.16 & -0.36 & -0.11 & -0.11 & -0.25 & -0.08 & 0.03 & -0.14 & -0.75 \\
\hline Oil crops & -0.11 & -0.11 & -0.17 & -0.10 & -0.14 & -0.16 & -0.21 & -0.08 & -0.06 & -0.12 & -0.08 \\
\hline Fruits (temp.) & -0.11 & -0.02 & -0.07 & -0.12 & -0.21 & -0.07 & -0.07 & -0.17 & -0.12 & -0.15 & -0.14 \\
\hline Legumes & -0.07 & -0.01 & -0.04 & -0.04 & -0.24 & -0.25 & -0.06 & -0.08 & -0.01 & -0.07 & -0.01 \\
\hline Other crops & -0.02 & -0.02 & -0.03 & -0.01 & -0.05 & -0.04 & -0.04 & -0.03 & -0.03 & -0.02 & -0.01 \\
\hline All commodities & -38.81 & -29.62 & -46.40 & -41.06 & -32.55 & -36.14 & -51.51 & -44.91 & -24.07 & -43.26 & -37.70 \\
\hline Fruit \&vegetables & -3.18 & -2.31 & -2.17 & -3.76 & -2.75 & -2.35 & -2.33 & -2.58 & -2.25 & -2.99 & -5.29 \\
\hline Red meat & -4.66 & -6.12 & -10.79 & -3.03 & -3.81 & -4.66 & -15.87 & -3.06 & -1.93 & -1.69 & -4.21 \\
\hline
\end{tabular}


Supplementary Table 11. Absolute change in per-capita food availability (kcal/d) by commodity and region. Regions include high-income countries (HIC), upper middle-income countries (UMC), lower middle-income countries (LMC), low-income countries (LIC); and the low and middle-income countries of Africa (AFR_LMIC), America (AMR_LMIC), the Eastern Mediterranean (EMR_LMIC), Europe (EUR_LMIC), South-East Asia (SEA_LMIC), and the Western

\section{Pacific (WPR_LMIC).}

\begin{tabular}{|c|c|c|c|c|c|c|c|c|c|c|c|}
\hline Food commodities & World & $\mathrm{HIC}$ & UMC & LMC & LIC & AFR_LMIC & AMR_LMIC & EMR_LMIC & EUR_LMIC & SEA_LMIC & WPR_LMIC \\
\hline Oils & -23.64 & -51.31 & -24.93 & -18.68 & -12.35 & -15.99 & -27.28 & -13.10 & -16.81 & -11.85 & -27.50 \\
\hline Wheat & -15.57 & -14.96 & -13.75 & -17.60 & -9.82 & -8.77 & -8.84 & -19.35 & -19.14 & -12.37 & -23.91 \\
\hline Rice & -13.97 & -2.92 & -6.40 & -17.50 & -18.89 & -8.95 & -8.62 & -5.12 & -1.34 & -19.03 & -27.14 \\
\hline Milk & -11.05 & -5.64 & -13.20 & -12.89 & -7.53 & -9.38 & -12.39 & -18.97 & -7.84 & -14.92 & -8.26 \\
\hline Beef & -6.63 & -6.45 & -16.84 & -4.42 & -6.08 & -7.70 & -24.96 & -4.42 & -2.44 & -2.11 & -6.46 \\
\hline Maize & -2.92 & -1.21 & -5.53 & -1.83 & -6.64 & -9.56 & -7.69 & -1.38 & -0.43 & -1.94 & -0.87 \\
\hline Other grains & -2.00 & -1.09 & -0.73 & -1.71 & -5.34 & -8.96 & -0.68 & -2.06 & -0.44 & -1.39 & -0.24 \\
\hline Sugar & -1.92 & -1.67 & -3.26 & -1.81 & -1.39 & -1.57 & -3.77 & -3.11 & -2.42 & -1.94 & -0.97 \\
\hline Pork & -1.70 & -4.02 & -2.06 & -1.27 & -0.59 & -0.47 & -2.90 & 0.00 & -0.92 & -0.15 & -3.07 \\
\hline Poultry & -1.13 & -1.33 & -1.99 & -1.07 & -0.33 & -0.32 & -2.75 & -0.52 & -0.65 & -0.26 & -2.23 \\
\hline Vegetables & -0.99 & -0.84 & -0.64 & -1.19 & -0.68 & -0.53 & -0.58 & -0.71 & -0.79 & -0.93 & -1.75 \\
\hline Lamb & -0.75 & -0.58 & -0.72 & -0.78 & -0.86 & -1.02 & -0.31 & -1.58 & -1.21 & -0.35 & -0.94 \\
\hline Eggs & -0.46 & -0.57 & -0.22 & -0.56 & -0.15 & -0.14 & -0.34 & -0.11 & 0.04 & -0.21 & -1.17 \\
\hline Fruits (trop.) & -0.40 & -0.24 & -0.35 & -0.36 & -0.77 & -0.82 & -0.53 & -0.51 & -0.09 & -0.41 & -0.23 \\
\hline Roots & -0.38 & -0.07 & -0.16 & -0.31 & -1.19 & -1.65 & -0.14 & -0.24 & -0.12 & -0.36 & -0.10 \\
\hline Oil crops & -0.36 & -0.39 & -0.31 & -0.35 & -0.45 & -0.54 & -0.37 & -0.19 & -0.16 & -0.29 & -0.46 \\
\hline Legumes & -0.23 & -0.05 & -0.13 & -0.16 & -0.81 & -0.86 & -0.21 & -0.31 & -0.02 & -0.23 & -0.02 \\
\hline Fruits (temp.) & -0.07 & -0.01 & -0.05 & -0.08 & -0.14 & -0.04 & -0.04 & -0.12 & -0.10 & -0.09 & -0.09 \\
\hline Other crops & -0.03 & -0.02 & -0.03 & -0.03 & -0.07 & -0.05 & -0.03 & -0.05 & -0.04 & -0.04 & -0.01 \\
\hline All commodities & -84.21 & -93.37 & -91.33 & -82.59 & -74.06 & -77.32 & -102.44 & -71.87 & -54.92 & -68.86 & -105.43 \\
\hline
\end{tabular}


Supplementary Table 12. Absolute changes in per-capita food consumption of red meat (g/d), fruits and vegetables (g/d), and food availability (kcal/d) by GHG tax scenario. The tax scenarios include scenarios that cover all commodities (TAX), exclude fruit and vegetables, staples, and legumes from taxation (TAXadj), focus on animal-based foods (meats, eggs, milk) (TAXani), focus on red meat (beef, lamb, pork) (TAXrem), focus on beef (TAXbef), and scenario variants in which income losses are compensated (_r scenarios), and variants in which three quarters of tax revenues are used to subsidise fruit and vegetable consumption (_s scenarios).

\begin{tabular}{lrrr}
\hline Scenario & $\begin{array}{c}\text { Red meat } \\
(\mathrm{g} / \mathrm{d})\end{array}$ & $\begin{array}{c}\text { Fruit\&veg } \\
(\mathrm{g} / \mathrm{d})\end{array}$ & $\begin{array}{c}\text { Energy } \\
\text { availability } \\
(\mathrm{kcal} / \mathrm{d})\end{array}$ \\
\hline TAX & -4.66 & -3.18 & -84.21 \\
TAXadj & -4.62 & -0.89 & -49.33 \\
TAXani & -4.99 & -0.83 & -25.85 \\
TAXrem & -5.17 & -0.44 & -10.69 \\
TAXbef & -3.63 & -0.32 & -6.37 \\
\hline TAX_r & -4.47 & -2.01 & -79.26 \\
TAXadj_r & -4.47 & 0.00 & -45.42 \\
TAXani_r & -4.85 & 0.00 & -22.17 \\
TAXrem_r & -5.08 & 0.00 & -8.55 \\
TAXbef_r & -3.57 & 0.00 & -4.74 \\
\hline TAX_s & -4.66 & 22.06 & -73.36 \\
TAXadj_s & -4.62 & 17.44 & -41.42 \\
TAXani_s & -4.99 & 16.08 & -18.46 \\
TAXrem_s & -5.17 & 9.73 & -6.26 \\
TAXbef_s & -3.63 & 7.12 & -3.15 \\
\hline TAXopt & -4.66 & 20.75 & -58.30 \\
\hline
\end{tabular}


Supplementary Table 13. Composition of TAXopt scenario (number or regions; percentage of regions). The individual tax scenarios include scenarios that cover all commodities (TAX), exclude fruit and vegetables, staples, and legumes from taxation (TAXadj), focus on animal-based foods (meats, eggs, milk) (TAXani), focus on red meat (beef, lamb, pork), focus on beef (TAXbef), and scenario variants in which income losses are compensated (_r scenarios), and variants in which three quarters of tax revenues are used to subsidise fruit and vegetable consumption (_s scenarios).

\begin{tabular}{|c|c|c|c|c|c|c|c|c|c|c|c|}
\hline Scenario & World & HIC & UMC & LMC & LIC & AFR_LMIC & AMR_LMIC & EMR_LMIC & EUR_LMIC & SEA_LMIC & WPR_LMIC \\
\hline TAX & $1(1 \%)$ & & $1(3 \%)$ & & & & & & & & $1(9 \%)$ \\
\hline TAXadj & $1(1 \%)$ & & & $1(2 \%)$ & & & & & & & $1(9 \%)$ \\
\hline \multicolumn{12}{|l|}{ TAXani } \\
\hline \multicolumn{12}{|l|}{ TAXrem } \\
\hline \multicolumn{12}{|l|}{ TAXbef } \\
\hline \multicolumn{12}{|l|}{ TAX_r } \\
\hline \multicolumn{12}{|l|}{ TAXadj_r } \\
\hline \multicolumn{12}{|l|}{ TAXani_r } \\
\hline TAXrem_r & $4(3 \%)$ & & & & $4(10 \%)$ & $4(10 \%)$ & & & & & \\
\hline \multicolumn{12}{|l|}{ TAXbef_r } \\
\hline TAX_s & $113(75 \%)$ & $35(100 \%)$ & $29(94 \%)$ & $37(84 \%)$ & $12(30 \%)$ & $14(35 \%)$ & $23(100 \%)$ & $12(86 \%)$ & $18(100 \%)$ & $4(44 \%)$ & $7(64 \%)$ \\
\hline TAXadj_s & $1(1 \%)$ & & & $1(2 \%)$ & & $1(3 \%)$ & & & & & \\
\hline TAXani_s & $20(13 \%)$ & & $1(3 \%)$ & $5(11 \%)$ & $14(35 \%)$ & $12(30 \%)$ & & $2(14 \%)$ & & $4(44 \%)$ & $2(18 \%)$ \\
\hline TAXrem_s & $9(6 \%)$ & & & & $9(23 \%)$ & $8(20 \%)$ & & & & $1(11 \%)$ & \\
\hline TAXbef_s & $1(1 \%)$ & & & & $1(3 \%)$ & $1(3 \%)$ & & & & & \\
\hline
\end{tabular}


Supplementary Table 14. Absolute change in food-related GHG emissions $\left(\mathrm{MtCO}_{2}\right.$-eq) in the TAX scenario by commodity and region. Regions include highincome countries (HIC), upper middle-income countries (UMC), lower middle-income countries (LMC), low-income countries (LIC); and the low and middleincome countries of Africa (AFR_LMIC), America (AMR_LMIC), the Eastern Mediterranean (EMR_LMIC), Europe (EUR_LMIC), South-East Asia (SEA_LMIC), and the Western Pacific (WPR_LMIC).

\begin{tabular}{|c|c|c|c|c|c|c|c|c|c|c|c|}
\hline Food commodities & World & $\mathrm{HIC}$ & UMC & LMC & LIC & AFR_LMIC & AMR_LMIC & EMR_LMIC & EUR_LMIC & SEA_LMIC & WPR_LMIC \\
\hline Beef & -632.97 & -54.37 & -266.40 & -224.34 & -87.86 & -99.10 & -263.34 & -38.09 & -3.99 & -81.65 & -92.44 \\
\hline Milk & -240.27 & -8.68 & -39.63 & -156.55 & -35.42 & -47.75 & -18.95 & -36.24 & -7.62 & -103.09 & -17.94 \\
\hline Lamb & -37.87 & -12.67 & -5.33 & -17.05 & -2.83 & -3.26 & -3.72 & -1.88 & -1.49 & -5.04 & -9.80 \\
\hline Oils & -27.13 & -2.07 & -3.44 & -16.07 & -5.55 & -6.41 & -1.00 & -5.09 & -1.98 & -4.20 & -6.36 \\
\hline Rice & -19.54 & -0.61 & -1.20 & -13.86 & -3.88 & -1.63 & -1.03 & -0.61 & -0.11 & -7.28 & -8.28 \\
\hline Pork & -11.91 & -2.31 & -2.94 & -6.12 & -0.54 & -0.46 & -2.55 & -0.57 & -0.45 & -0.90 & -4.68 \\
\hline Poultry & -11.03 & -5.12 & -2.02 & -3.49 & -0.40 & -0.29 & -1.83 & 0.00 & -0.44 & -0.20 & -3.15 \\
\hline Wheat & -9.22 & -1.49 & -1.18 & -5.73 & -0.82 & -0.69 & -0.49 & -1.01 & -0.68 & -1.92 & -2.95 \\
\hline Vegetables & -6.58 & -0.88 & -0.55 & -4.60 & -0.55 & -0.40 & -0.32 & -0.39 & -0.31 & -1.47 & -2.82 \\
\hline Eggs & -3.57 & -0.67 & -0.25 & -2.45 & -0.19 & -0.22 & -0.23 & -0.06 & 0.01 & -0.38 & -2.01 \\
\hline Other grains & -1.01 & -0.10 & -0.06 & -0.48 & -0.38 & -0.57 & -0.04 & -0.08 & -0.01 & -0.18 & -0.03 \\
\hline Maize & -0.88 & -0.06 & -0.22 & -0.32 & -0.27 & -0.35 & -0.19 & -0.03 & -0.01 & -0.17 & -0.06 \\
\hline Fruits (trop.) & -0.55 & -0.06 & -0.07 & -0.29 & -0.13 & -0.12 & -0.07 & -0.06 & -0.01 & -0.15 & -0.08 \\
\hline Sugar & -0.39 & -0.05 & -0.09 & -0.21 & -0.04 & -0.04 & -0.06 & -0.05 & -0.03 & -0.10 & -0.04 \\
\hline Roots & -0.12 & 0.00 & -0.01 & -0.06 & -0.05 & -0.06 & 0.00 & -0.01 & 0.00 & -0.03 & -0.01 \\
\hline Oil crops & -0.10 & -0.01 & -0.02 & -0.05 & -0.02 & -0.02 & -0.02 & -0.01 & 0.00 & -0.03 & -0.02 \\
\hline Fruits (temp.) & -0.07 & 0.00 & -0.01 & -0.05 & -0.02 & -0.01 & 0.00 & -0.01 & 0.00 & -0.03 & -0.02 \\
\hline Legumes & -0.05 & 0.00 & 0.00 & -0.02 & -0.02 & -0.02 & 0.00 & -0.01 & 0.00 & -0.01 & 0.00 \\
\hline All commodities & $-1,003.28$ & -89.16 & -323.42 & -451.72 & -138.98 & -161.39 & -293.85 & -84.20 & -17.13 & -206.83 & -150.72 \\
\hline
\end{tabular}


Supplementary Table 15. Percentage change in food-related GHG emissions in the TAX scenario by commodity and region. Regions include high-income countries (HIC), upper middle-income countries (UMC), lower middle-income countries (LMC), low-income countries (LIC); and the low and middle-income

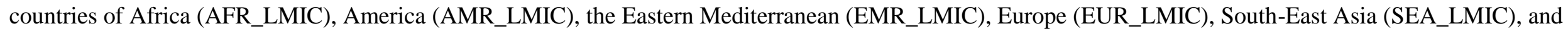
the Western Pacific (WPR_LMIC).

\begin{tabular}{|c|c|c|c|c|c|c|c|c|c|c|c|}
\hline Food commodities & World & $\mathrm{HIC}$ & UMC & LMC & LIC & AFR_LMIC & AMR_LMIC & EMR_LMIC & EUR_LMIC & SEA_LMIC & WPR_LMIC \\
\hline Beef & -16.5 & -7.1 & -20.0 & -16.9 & -21.0 & -21.9 & -21.7 & -13.8 & -3.5 & -22.9 & -13.9 \\
\hline Milk & -10.2 & -2.1 & -8.4 & -12.7 & -14.9 & -17.8 & -6.7 & -10.8 & -4.4 & -15.4 & -8.5 \\
\hline Oils & -8.6 & -11.3 & -7.5 & -7.7 & -7.7 & -6.9 & -8.7 & -5.8 & -5.3 & -5.7 & -10.9 \\
\hline Lamb & -5.8 & -4.2 & -6.4 & -5.3 & -8.6 & -7.9 & -7.2 & -6.0 & -5.5 & -7.7 & -4.2 \\
\hline Wheat & -2.8 & -2.3 & -2.1 & -3.2 & -3.5 & -3.4 & -2.3 & -1.9 & -1.7 & -3.1 & -4.4 \\
\hline Rice & -2.8 & -1.8 & -3.2 & -2.7 & -3.0 & -4.0 & -3.2 & -2.6 & -2.3 & -2.2 & -3.4 \\
\hline Poultry & -2.0 & -2.3 & -1.7 & -1.8 & -2.6 & -2.4 & -2.7 & -1.5 & -0.7 & -1.6 & -1.6 \\
\hline Other grains & -2.0 & -1.3 & -2.0 & -2.6 & -2.1 & -1.9 & -2.4 & -1.7 & -1.2 & -1.5 & -3.1 \\
\hline Pork & -2.0 & -1.6 & -1.8 & -1.8 & -2.5 & -2.4 & -1.8 & -1.0 & -0.5 & -2.3 & -1.5 \\
\hline Maize & -1.6 & -2.4 & -2.9 & -0.9 & -1.3 & -2.6 & -3.9 & 0.0 & -1.5 & -1.0 & -0.8 \\
\hline Eggs & -1.4 & -1.3 & -0.7 & -1.5 & -2.2 & -1.7 & -1.0 & -0.8 & 0.1 & -1.5 & -1.6 \\
\hline Vegetables & -1.0 & -0.9 & -0.9 & -0.9 & -1.6 & -1.3 & -1.3 & -0.8 & -0.7 & -1.3 & -0.9 \\
\hline Sugar & -0.8 & -0.5 & -0.8 & -0.9 & -1.4 & -1.2 & -0.9 & -1.1 & -0.7 & -0.9 & -0.8 \\
\hline Oil crops & -0.6 & -0.7 & -1.1 & -0.4 & -1.0 & -0.9 & -1.2 & -1.0 & -0.7 & -0.6 & -0.2 \\
\hline Fruits (trop.) & -0.5 & -0.3 & -0.4 & -0.5 & -1.1 & -0.8 & -0.4 & -0.8 & -0.3 & -0.6 & -0.4 \\
\hline Legumes & -0.4 & -0.1 & -0.2 & -0.3 & -0.9 & -0.8 & -0.2 & -0.4 & -0.1 & -0.3 & -0.1 \\
\hline Fruits (temp.) & -0.3 & 0.0 & -0.2 & -0.3 & -1.0 & -0.6 & -0.3 & -0.4 & -0.1 & -0.8 & -0.3 \\
\hline Roots & -0.3 & -0.1 & -0.1 & -0.2 & -0.6 & -0.4 & -0.2 & -0.5 & -0.1 & -0.5 & -0.1 \\
\hline All commodities & -9.3 & -4.4 & -13.5 & -8.6 & -13.0 & -15.2 & -15.8 & -9.1 & -3.2 & -11.2 & -6.1 \\
\hline
\end{tabular}


Supplementary Table 16. Absolute change in food-related GHG emissions $\left(\mathrm{MtCO}_{2}\right.$-eq) in the TAXopt scenario by commodity and region. Regions include high-income countries (HIC), upper middle-income countries (UMC), lower middle-income countries (LMC), low-income countries (LIC); and the low and middle-income countries of Africa (AFR_LMIC), America (AMR_LMIC), the Eastern Mediterranean (EMR_LMIC), Europe (EUR_LMIC), South-East Asia (SEA_LMIC), and the Western Pacific (WPR_LMIC).

\begin{tabular}{|c|c|c|c|c|c|c|c|c|c|c|c|}
\hline Food commodities & World & $\mathrm{HIC}$ & UMC & LMC & LIC & AFR_LMIC & AMR_LMIC & EMR_LMIC & EUR_LMIC & SEA_LMIC & WPR_LMIC \\
\hline Beef & -632.19 & -54.37 & -266.41 & -224.54 & -86.87 & -98.34 & -263.34 & -38.08 & -3.99 & -81.60 & -92.46 \\
\hline Milk & -221.94 & -8.68 & -39.63 & -157.30 & -16.33 & -29.45 & -18.95 & -36.28 & -7.62 & -103.02 & -17.94 \\
\hline Lamb & -32.04 & -12.67 & -5.32 & -13.34 & -0.71 & -0.89 & -3.72 & -1.79 & -1.49 & -1.70 & -9.78 \\
\hline Oils & -26.95 & -2.07 & -3.44 & -16.11 & -5.33 & -6.20 & -1.00 & -5.10 & -1.98 & -4.22 & -6.36 \\
\hline Rice & -13.08 & -0.61 & -1.20 & -10.39 & -0.88 & -0.50 & -1.03 & -0.57 & -0.11 & -2.19 & -8.08 \\
\hline Pork & -11.74 & -2.31 & -2.94 & -6.10 & -0.39 & -0.34 & -2.55 & -0.57 & -0.45 & -0.85 & -4.68 \\
\hline Poultry & -10.96 & -5.12 & -2.02 & -3.50 & -0.33 & -0.23 & -1.83 & 0.00 & -0.44 & -0.19 & -3.16 \\
\hline Wheat & -7.07 & -1.49 & -1.18 & -4.09 & -0.30 & -0.31 & -0.49 & -0.88 & -0.68 & -0.28 & -2.95 \\
\hline Vegetables & -3.54 & -0.67 & -0.25 & -2.47 & -0.15 & -0.19 & -0.23 & -0.06 & 0.01 & -0.39 & -2.01 \\
\hline Eggs & -0.57 & -0.06 & -0.22 & -0.24 & -0.04 & -0.10 & -0.19 & -0.03 & -0.01 & -0.12 & -0.06 \\
\hline Other grains & -0.35 & -0.10 & -0.06 & -0.13 & -0.07 & -0.10 & -0.04 & -0.08 & -0.01 & 0.00 & -0.03 \\
\hline Maize & -0.31 & -0.05 & -0.09 & -0.15 & -0.02 & -0.02 & -0.06 & -0.05 & -0.03 & -0.05 & -0.04 \\
\hline Fruits (trop.) & -0.13 & -0.01 & -0.05 & -0.04 & -0.03 & -0.03 & -0.04 & -0.01 & 0.00 & -0.02 & 0.00 \\
\hline Sugar & -0.07 & -0.01 & -0.02 & -0.03 & -0.01 & -0.01 & -0.02 & -0.01 & 0.00 & -0.01 & -0.02 \\
\hline Roots & -0.07 & 0.00 & -0.01 & -0.04 & -0.02 & -0.02 & 0.00 & -0.01 & 0.00 & -0.02 & -0.01 \\
\hline Oil crops & 1.87 & 0.79 & 0.39 & 0.58 & 0.12 & 0.08 & 0.25 & 0.11 & 0.14 & 0.12 & 0.39 \\
\hline Fruits (temp.) & 5.38 & 1.58 & 1.96 & 1.62 & 0.22 & 0.32 & 1.74 & 0.45 & 0.06 & 0.50 & 0.72 \\
\hline Legumes & 34.54 & 8.36 & 7.24 & 16.87 & 2.08 & 2.39 & 5.13 & 1.81 & 1.85 & 3.27 & 11.74 \\
\hline All commodities & -919.21 & -77.51 & -313.24 & -419.39 & -109.07 & -133.93 & -286.37 & -81.15 & -14.76 & -190.77 & -134.74 \\
\hline
\end{tabular}


Supplementary Table 17. Percentage change in food-related GHG emissions in the TAXopt scenario by commodity and region. Regions include high-income countries (HIC), upper middle-income countries (UMC), lower middle-income countries (LMC), low-income countries (LIC); and the low and middle-income countries of Africa (AFR_LMIC), America (AMR_LMIC), the Eastern Mediterranean (EMR_LMIC), Europe (EUR_LMIC), South-East Asia (SEA_LMIC), and the Western Pacific (WPR_LMIC).

\begin{tabular}{|c|c|c|c|c|c|c|c|c|c|c|c|}
\hline Food commodities & World & $\mathrm{HIC}$ & UMC & LMC & LIC & AFR_LMIC & AMR_LMIC & EMR_LMIC & EUR_LMIC & SEA_LMIC & WPR_LMIC \\
\hline Beef & -16.4 & -7.1 & -20.0 & -16.9 & -20.8 & -21.8 & -21.7 & -13.8 & -3.5 & -22.9 & -13.9 \\
\hline Milk & -9.4 & -2.1 & -8.4 & -12.8 & -6.9 & -11.0 & -6.7 & -10.8 & -4.4 & -15.4 & -8.5 \\
\hline Oils & -7.3 & -11.3 & -7.5 & -6.0 & -1.9 & -1.9 & -8.7 & -5.5 & -5.3 & -1.9 & -10.9 \\
\hline Lamb & -5.7 & -4.2 & -6.4 & -5.3 & -8.3 & -7.7 & -7.2 & -6.0 & -5.5 & -7.7 & -4.2 \\
\hline Wheat & -2.2 & -2.3 & -2.1 & -2.3 & -1.3 & -1.5 & -2.3 & -1.7 & -1.7 & -0.5 & -4.3 \\
\hline Rice & -2.0 & -1.3 & -2.0 & -2.6 & -1.6 & -1.4 & -2.4 & -1.7 & -1.2 & -1.5 & -3.1 \\
\hline Poultry & -1.8 & -1.8 & -3.2 & -2.1 & -0.7 & -1.2 & -3.2 & -2.4 & -2.3 & -0.7 & -3.3 \\
\hline Other grains & -1.6 & -2.4 & -2.9 & -0.9 & -1.1 & -2.0 & -3.9 & -0.1 & -1.5 & -1.0 & -0.8 \\
\hline Pork & -1.4 & -1.3 & -0.7 & -1.5 & -1.7 & -1.5 & -1.0 & -0.8 & 0.1 & -1.5 & -1.6 \\
\hline Maize & -1.3 & -1.6 & -1.8 & -1.4 & -0.4 & -0.7 & -1.8 & -0.9 & -0.5 & -1.6 & -1.4 \\
\hline Eggs & -0.9 & -1.3 & -1.9 & -0.5 & -0.9 & -1.0 & -2.2 & -1.1 & -0.4 & -0.4 & -0.6 \\
\hline Vegetables & -0.7 & -2.3 & -1.6 & -0.5 & -0.5 & -0.4 & -2.7 & -1.5 & -0.7 & 0.0 & -1.6 \\
\hline Sugar & -0.7 & -0.5 & -0.8 & -0.7 & -0.7 & -0.6 & -0.9 & -1.1 & -0.7 & -0.4 & -0.8 \\
\hline Oil crops & -0.4 & -0.7 & -1.1 & -0.3 & -0.4 & -0.3 & -1.2 & -1.0 & -0.7 & -0.3 & -0.2 \\
\hline Fruits (trop.) & -0.2 & -0.1 & -0.1 & -0.2 & -0.2 & -0.2 & -0.2 & -0.5 & -0.1 & -0.3 & -0.1 \\
\hline Legumes & 5.0 & 9.0 & 10.5 & 2.8 & 1.8 & 2.1 & 10.5 & 5.5 & 2.2 & 2.0 & 3.4 \\
\hline Fruits (temp.) & 5.1 & 8.8 & 11.6 & 3.4 & 6.0 & 7.7 & 20.6 & 3.8 & 4.2 & 3.0 & 3.6 \\
\hline Roots & 6.7 & 9.0 & 9.6 & 4.4 & 6.1 & 8.2 & 21.1 & 4.5 & 4.1 & 3.4 & 5.0 \\
\hline All commodities & -8.6 & -3.8 & -13.0 & -8.0 & -10.2 & -12.6 & -15.4 & -8.8 & -2.8 & -10.4 & -5.4 \\
\hline
\end{tabular}


Supplementary Table 18. Absolute change in food-related GHG emissions $\left(\mathrm{MtCO}_{2}\right.$-eq) and GHG tax revenues by tax scenario The tax scenarios include scenarios that cover all commodities (TAX), exclude fruit and vegetables, staples, and legumes from taxation (TAXadj), focus on animal-based foods (meats, eggs, milk) (TAXani), focus on red meat (beef, lamb, pork), focus on beef (TAXbef), scenario variants in which income losses are compensated (_r scenarios), variants in which three quarters of tax revenues are used to subsidise fruit and vegetable consumption (_s scenarios), and a regionally optimised scenario (TAXopt) in which region adopts that scenario that maximises its health benefits (Supplementary Table 13).

\begin{tabular}{lrr} 
Scenario & $\begin{array}{l}\text { Emissions reductions } \\
\text { (MtCO2-eq) }\end{array}$ & $\begin{array}{l}\text { GHG tax revenues } \\
\text { (USD million) }\end{array}$ \\
\hline TAX & $-1,003$ & 505,340 \\
TAXadj & -962 & 403,469 \\
TAXani & -959 & 377,386 \\
TAXrem & -689 & 223,891 \\
TAXbef & -657 & 164,612 \\
\hline TAX_r & -970 & 507,057 \\
TAXadj_r & -935 & 404,730 \\
TAXani_r & -934 & 378,525 \\
TAXrem_r & -673 & 224,392 \\
TAXbef_r & -645 & 164,942 \\
\hline TAX_s & -952 & 508,021 \\
TAXadj_s & -926 & 403,469 \\
TAXani_s & -925 & 377,386 \\
TAXrem_s & -668 & 223,891 \\
TAXbef_s & -642 & 164,612 \\
\hline TAXopt & -919 & 466,553 \\
\hline
\end{tabular}


Supplementary text on tax revenues: Tax revenues from imposing GHG taxes amounted to $\$ 505$ billion per year globally under full coverage, and to $\$ 467$ billion in the regionally optimised combination of tax scenarios (Supplementary Tables 19-20). A third ( $\$ 167$ billion) of all revenues stemmed from GHG taxes on beef, a fifth (\$105-100 billion) from milk products, and 5-8\% each from pork, rice, vegetables, poultry, and lamb. Across regions, the tax revenues ranged from $\$ 27$ billion in the LMICs of Europe to $\$ 121$ billion in the LMICs of the Western Pacific. Two thirds of the revenues (\$332-356 billion) were raised in middle-income countries, a fifth (\$101-102 billion) in high-income countries, and up to a tenth (\$3348 billion) in low-income countries with the greater portion being raised in the scenario with full coverage.

Supplementary Table 19. GHG tax revenues (USD million) in the TAX scenario by commodity and region. Regions include high-income countries (HIC), upper middle-income countries (UMC), lower middle-income countries (LMC), low-income countries (LIC); and the low and middle-income countries of Africa (AFR_LMIC), America (AMR_LMIC), the Eastern Mediterranean (EMR_LMIC), Europe (EUR_LMIC), South-East Asia (SEA_LMIC), and the Western Pacific (WPR_LMIC).

\begin{tabular}{|c|c|c|c|c|c|c|c|c|c|c|c|}
\hline Food commodities & World & $\mathrm{HIC}$ & UMC & LMC & LIC & AFR_LMIC & AMR_LMIC & EMR_LMIC & EUR_LMIC & SEA_LMIC & WPR_LMIC \\
\hline Beef & 166,588 & 36,834 & 55,198 & 57,399 & 17,158 & 18,285 & 49,401 & 12,337 & 5,714 & 14,239 & 29,778 \\
\hline Milk & 110,209 & 21,432 & 22,555 & 55,764 & 10,457 & 11,448 & 13,773 & 15,600 & 8,611 & 29,293 & 10,052 \\
\hline Pork & 35,748 & 1,713 & 1,904 & 25,526 & 6,605 & 2,047 & 1,593 & 1,185 & 235 & 16,588 & 12,387 \\
\hline Rice & 35,656 & 10,608 & 3,516 & 19,936 & 1,596 & 571 & 2,362 & 5 & 1,447 & 971 & 19,691 \\
\hline Vegetables & 35,067 & 4,889 & 3,201 & 25,206 & 1,771 & 1,582 & 1,275 & 2,461 & 2,257 & 5,605 & 16,998 \\
\hline Poultry & 30,226 & 9,405 & 7,654 & 11,879 & 1,287 & 1,218 & 5,398 & 1,711 & 1,874 & 2,969 & 7,651 \\
\hline Lamb & 23,018 & 2,465 & 2,626 & 14,869 & 3,057 & 3,871 & 675 & 4,138 & 1,758 & 2,625 & 7,485 \\
\hline Oils & 20,950 & 5,142 & 3,400 & 10,647 & 1,761 & 2,287 & 2,037 & 1,589 & 1,379 & 4,353 & 4,163 \\
\hline Wheat & 16,481 & 3,236 & 2,921 & 9,129 & 1,195 & 1,027 & 1,065 & 2,645 & 2,058 & 3,086 & 3,364 \\
\hline Eggs & 13,240 & 2,686 & 1,874 & 8,236 & 443 & 644 & 1,198 & 422 & 670 & 1,328 & 6,292 \\
\hline Fruits (trop.) & 5,526 & 909 & 962 & 3,012 & 642 & 793 & 856 & 424 & 148 & 1,298 & 1,097 \\
\hline Other grains & 2,518 & 212 & 181 & 1,384 & 740 & 1,198 & 68 & 270 & 109 & 561 & 100 \\
\hline Roots & 2,388 & 332 & 315 & 1,302 & 439 & 698 & 156 & 82 & 192 & 346 & 583 \\
\hline Sugar & 2,348 & 504 & 548 & 1,149 & 147 & 166 & 352 & 254 & 211 & 592 & 268 \\
\hline Maize & 2,286 & 204 & 634 & 889 & 559 & 729 & 533 & 174 & 70 & 363 & 211 \\
\hline Fruits (temp.) & 1,448 & 454 & 210 & 686 & 98 & 48 & 62 & 130 & 173 & 177 & 405 \\
\hline Oil crops & 951 & 110 & 96 & 657 & 87 & 98 & 68 & 31 & 20 & 232 & 390 \\
\hline Legumes & 692 & 57 & 124 & 363 & 148 & 150 & 104 & 64 & 24 & 254 & 39 \\
\hline All commodities & 505,340 & 101,194 & 107,919 & 248,036 & 48,190 & 46,860 & 80,978 & 43,522 & 26,950 & 84,882 & 120,953 \\
\hline
\end{tabular}


Supplementary Table 20. GHG tax revenues (USD million) in the TAXopt scenario by commodity and region. Regions include high-income countries (HIC), upper middle-income countries (UMC), lower middle-income countries (LMC), low-income countries (LIC); and the low and middle-income countries of Africa (AFR_LMIC), America (AMR_LMIC), the Eastern Mediterranean (EMR_LMIC), Europe (EUR_LMIC), South-East Asia (SEA_LMIC), and the Western

\section{Pacific (WPR_LMIC).}

\begin{tabular}{|c|c|c|c|c|c|c|c|c|c|c|c|}
\hline Food commodities & World & HIC & UMC & LMC & LIC & AFR_LMIC & AMR_LMIC & EMR_LMIC & EUR_LMIC & SEA_LMIC & WPR_LMIC \\
\hline Beef & 166,629 & 36,834 & 55,198 & 57,389 & 17,209 & 18,325 & 49,401 & 12,337 & 5,714 & 14,241 & 29,777 \\
\hline Milk & 105,332 & 21,432 & 22,555 & 55,725 & 5,620 & 6,986 & 13,773 & 15,598 & 8,611 & 28,880 & 10,052 \\
\hline Pork & 35,582 & 10,608 & 3,516 & 19,936 & 1,522 & 497 & 2,362 & 5 & 1,447 & 972 & 19,690 \\
\hline Rice & 30,670 & 5,369 & 3,602 & 21,000 & 699 & 544 & 1,558 & 2,512 & 2,369 & 628 & 17,691 \\
\hline Vegetables & 30,063 & 9,405 & 7,654 & 11,880 & 1,123 & 1,061 & 5,398 & 1,711 & 1,874 & 2,963 & 7,651 \\
\hline Poultry & 22,949 & 2,465 & 2,626 & 14,867 & 2,990 & 3,804 & 675 & 4,137 & 1,758 & 2,624 & 7,485 \\
\hline Lamb & 21,138 & 1,713 & 1,901 & 15,927 & 1,596 & 454 & 1,593 & 1,114 & 235 & 3,966 & 12,063 \\
\hline Oils & 15,672 & 5,142 & 3,393 & 6,703 & 434 & 617 & 2,037 & 1,543 & 1,379 & 804 & 4,150 \\
\hline Wheat & 13,128 & 2,686 & 1,874 & 8,235 & 333 & 540 & 1,198 & 422 & 670 & 1,321 & 6,292 \\
\hline Eggs & 12,994 & 3,236 & 2,918 & 6,364 & 475 & 488 & 1,065 & 2,466 & 2,058 & 320 & 3,361 \\
\hline Fruits (trop.) & 4,279 & 994 & 1,067 & 2,022 & 196 & 217 & 950 & 447 & 152 & 412 & 1,106 \\
\hline Other grains & 1,761 & 504 & 547 & 658 & 52 & 61 & 352 & 250 & 211 & 116 & 265 \\
\hline Roots & 1,555 & 332 & 314 & 803 & 105 & 148 & 156 & 79 & 192 & 77 & 571 \\
\hline Sugar & 1,552 & 204 & 632 & 664 & 52 & 170 & 533 & 171 & 70 & 199 & 205 \\
\hline Maize & 1,341 & 495 & 230 & 570 & 47 & 21 & 75 & 127 & 180 & 18 & 425 \\
\hline Fruits (temp.) & 839 & 212 & 180 & 395 & 52 & 84 & 68 & 265 & 109 & 1 & 100 \\
\hline Oil crops & 757 & 110 & 96 & 527 & 23 & 19 & 68 & 31 & 20 & 120 & 387 \\
\hline Legumes & 311 & 56 & 122 & 122 & 11 & 17 & 102 & 63 & 24 & 12 & 38 \\
\hline All commodities & 466,553 & 101,799 & 108,425 & 223,788 & 32,541 & 34,054 & 81,366 & 43,279 & 27,073 & 57,674 & 121,309 \\
\hline
\end{tabular}


Supplementary Table 21. Avoided deaths (in thousands) by region, scenario, and risk factor (mean: mean values; std: standard deviation). Risk factors include an aggregate of moderate and severe stunting (STN), all risks combined including stunting (ALL_STN), and all risks combined excluding stunting (ALL_SCN).

\begin{tabular}{|c|c|c|c|c|c|c|c|c|c|c|c|}
\hline Parameter & World & HIC & UMC & LMC & LIC & AFR_LMIC & AMR_LMIC & EMR_LMIC & EUR_LMIC & SEA_LMIC & WPR_LMIC \\
\hline \multicolumn{12}{|l|}{$T A X$} \\
\hline \multicolumn{12}{|c|}{ ALL_SCN } \\
\hline mean & 106.54 & 37.14 & 59.26 & 24.01 & -13.87 & 48.01 & -4.45 & 7.44 & 13.60 & -20.76 & 25.56 \\
\hline std & 11.21 & 2.31 & 1.30 & 10.78 & 1.57 & 1.15 & 1.02 & 1.11 & 0.56 & 9.30 & 5.47 \\
\hline \multicolumn{12}{|c|}{ ALL_STN } \\
\hline mean & 103.34 & 37.14 & 58.99 & 21.64 & -14.43 & 47.83 & -5.47 & 6.99 & 13.52 & -21.86 & 25.19 \\
\hline std & 11.21 & 2.31 & 1.30 & 10.78 & 1.57 & 1.15 & 1.02 & 1.11 & 0.56 & 9.30 & 5.47 \\
\hline \multicolumn{12}{|l|}{ STN } \\
\hline mean & -3.20 & 0.00 & -0.27 & -2.36 & -0.56 & -0.18 & -1.01 & -0.45 & -0.09 & -1.10 & -0.37 \\
\hline std & 0.33 & 0.00 & 0.07 & 0.32 & 0.02 & 0.06 & 0.06 & 0.04 & 0.02 & 0.13 & 0.29 \\
\hline \multicolumn{12}{|l|}{ TAXopt } \\
\hline \multicolumn{12}{|c|}{ ALL_SCN } \\
\hline mean & 509.48 & 115.81 & 126.36 & 252.58 & 14.73 & 88.33 & 18.39 & 18.99 & 40.64 & 29.53 & 197.78 \\
\hline std & 17.08 & 2.32 & 1.32 & 16.87 & 0.45 & 1.16 & 0.34 & 0.91 & 0.61 & 3.19 & 16.54 \\
\hline \multicolumn{12}{|c|}{ ALL_STN } \\
\hline mean & 507.75 & 115.81 & 126.15 & 251.25 & 14.54 & 88.19 & 18.00 & 18.63 & 40.57 & 29.09 & 197.47 \\
\hline std & 17.08 & 2.32 & 1.32 & 16.87 & 0.45 & 1.16 & 0.34 & 0.91 & 0.61 & 3.19 & 16.54 \\
\hline \multicolumn{12}{|l|}{ STN } \\
\hline mean & -1.73 & 0.00 & -0.21 & -1.33 & -0.18 & -0.15 & -0.39 & -0.36 & -0.07 & -0.44 & -0.32 \\
\hline std & 0.27 & 0.00 & 0.06 & 0.26 & 0.01 & 0.05 & 0.04 & 0.03 & 0.02 & 0.05 & 0.25 \\
\hline
\end{tabular}


Supplementary Table 22. Health impacts under different metrics.

\begin{tabular}{|c|c|c|c|c|c|c|c|c|c|c|c|c|}
\hline \multirow{2}{*}{ Scenario } & \multirow{2}{*}{ World } & \multicolumn{2}{|c|}{ Positively affected } & \multicolumn{2}{|c|}{ Negatively affected } & \multirow{2}{*}{$\begin{array}{l}\text { High-income } \\
\text { countries }\end{array}$} & \multirow{2}{*}{$\begin{array}{c}\text { LMICs } \\
\text { Americas }\end{array}$} & \multirow{2}{*}{$\begin{array}{l}\text { LMICs } \\
\text { Africa }\end{array}$} & \multirow{2}{*}{$\begin{array}{c}\text { LMICs } \\
\text { Eastern } \\
\text { Mediterranean }\end{array}$} & \multirow{2}{*}{$\begin{array}{l}\text { LMICs } \\
\text { Europe }\end{array}$} & \multirow{2}{*}{$\begin{array}{c}\text { LMICs } \\
\text { South-East } \\
\text { Asia }\end{array}$} & \multirow{2}{*}{$\begin{array}{c}\text { LMICs } \\
\text { Western } \\
\text { Pacific }\end{array}$} \\
\hline & & abs & count & abs & count & & & & & & & \\
\hline $\begin{array}{l}\text { TAX } \\
\text { Avoided } \\
\text { deaths } \\
\text { (thousands) }\end{array}$ & 106.54 & 145.79 & 115 & -39.26 & 35 & 37.14 & 48.01 & -4.45 & 7.44 & 13.60 & -20.76 & 25.56 \\
\hline $\begin{array}{l}\text { Avoided } \\
\text { premature } \\
\text { deaths } \\
\text { (thousands) }\end{array}$ & 23.76 & 45.34 & 112 & -21.59 & 38 & 7.76 & 18.59 & -4.00 & 2.52 & 5.02 & -12.10 & 5.96 \\
\hline $\begin{array}{l}\text { Years of life } \\
\text { saved } \\
\text { (thousands) }\end{array}$ & 1180.19 & 2596.03 & 111 & -1415.84 & 39 & 560.50 & 975.46 & -394.09 & 111.31 & 271.65 & -729.01 & 384.37 \\
\hline $\begin{array}{l}\text { Disability- } \\
\text { adjusted life- } \\
\text { years saved } \\
\text { (thousands) }\end{array}$ & 1224.71 & 3417.41 & 110 & -2192.70 & 39 & 718.37 & 1395.39 & -582.91 & 133.74 & 357.79 & -1210.66 & 412.99 \\
\hline TAXopt & & & & & & & & & & & & \\
\hline $\begin{array}{l}\text { Avoided } \\
\text { deaths } \\
\text { (thousands) }\end{array}$ & 509.48 & 509.48 & 150 & 0.00 & 0 & 115.81 & 88.33 & 18.39 & 18.99 & 40.64 & 29.53 & 197.78 \\
\hline $\begin{array}{l}\text { Avoided } \\
\text { premature } \\
\text { deaths } \\
\text { (thousands) }\end{array}$ & 188.53 & 188.57 & 147 & -0.03 & 3 & 27.46 & 36.14 & 8.91 & 8.25 & 16.53 & 14.78 & 76.47 \\
\hline $\begin{array}{l}\text { Years of life } \\
\text { saved } \\
\text { (thousands) }\end{array}$ & 9785.70 & 9795.03 & 143 & -9.33 & 7 & 1806.48 & 1845.20 & 395.06 & 410.94 & 837.90 & 626.78 & 3863.34 \\
\hline $\begin{array}{l}\text { Disability- } \\
\text { adjusted life- } \\
\text { years saved } \\
\text { (thousands) }\end{array}$ & 13674.31 & 13691.09 & 141 & -16.78 & 8 & 2388.33 & 2672.45 & 517.07 & 602.12 & 1116.73 & 863.59 & 5514.03 \\
\hline
\end{tabular}


Supplementary Table 23. Negative health impacts under different metrics by country (mean: mean value; CI: 95\% confidence interval).

\begin{tabular}{|c|c|c|c|c|c|c|c|c|}
\hline \multirow[t]{2}{*}{ Country } & \multicolumn{2}{|c|}{ Deaths avoided (thousands) } & \multicolumn{2}{|c|}{$\begin{array}{l}\text { Premature deaths avoided } \\
\text { (thousands) }\end{array}$} & \multicolumn{2}{|l|}{$\begin{array}{l}\text { Years of life saved } \\
\text { (thousands) }\end{array}$} & \multicolumn{2}{|c|}{$\begin{array}{l}\text { Disability-adjusted life- } \\
\text { years saved (thousands) }\end{array}$} \\
\hline & mean & CI & mean & $\mathrm{CI}$ & mean & $\mathrm{CI}$ & mean & CI \\
\hline Ethiopia & 0.02 & 0.09 & -0.00 & 0.05 & -3.70 & 2.93 & -6.40 & 4.47 \\
\hline Central African Republic & 0.04 & 0.05 & -0.03 & 0.04 & -3.64 & 2.32 & -5.30 & 3.07 \\
\hline Zimbabwe & 0.23 & 0.05 & 0.01 & 0.04 & -0.73 & 2.57 & -2.59 & 3.58 \\
\hline Uganda & 0.05 & 0.02 & 0.00 & 0.02 & -0.88 & 1.15 & -1.57 & 1.56 \\
\hline Malawi & 0.02 & 0.01 & -0.00 & 0.01 & -0.17 & 0.28 & -0.35 & 0.39 \\
\hline Burundi & 0.00 & 0.00 & 0.00 & 0.00 & -0.16 & 0.17 & -0.25 & 0.24 \\
\hline Congo & 0.05 & 0.01 & 0.01 & 0.01 & 0.11 & 0.56 & -0.16 & 0.81 \\
\hline Eritrea & 0.01 & 0.00 & 0.00 & 0.00 & -0.04 & 0.15 & -0.15 & 0.23 \\
\hline
\end{tabular}


Supplementary Table 24. Health impacts in terms of avoided deaths (thousands) in TAXopt scenario for lower (50\%) and greater (100\%) proportions of GHG tax revenues used to subsidies fruit and vegetable consumption.

\begin{tabular}{|c|c|c|c|c|c|c|c|c|c|c|c|c|}
\hline $\begin{array}{l}\text { Revenue } \\
\text { used for } \\
\text { subsidies }\end{array}$ & World & $\begin{array}{l}\text { Posit } \\
\text { affe } \\
\text { abs }\end{array}$ & $\begin{array}{l}\text { vely } \\
\text { ted }\end{array}$ & $\begin{array}{r}\text { Negativ } \\
\text { affect } \\
\text { abs }\end{array}$ & \# & HIC & AFR_LMIC & AMR_LMIC & EMR_LMIC & EUR_LMIC & SEA_LMIC & WPR_LMIC \\
\hline \multicolumn{13}{|l|}{$75 \%$} \\
\hline mean & 509.48 & 509.48 & 150.00 & 0.00 & 0.00 & 115.81 & 18.39 & 88.33 & 18.99 & 40.64 & 29.53 & 197.78 \\
\hline std & 17.08 & 17.08 & & & & 2.32 & 0.34 & 1.16 & 0.91 & 0.61 & 3.19 & 16.54 \\
\hline \multicolumn{13}{|l|}{$50 \%$} \\
\hline mean & 395.96 & 395.98 & 149.00 & -0.02 & 1.00 & 90.67 & 14.52 & 74.18 & 15.66 & 32.28 & 20.68 & 147.98 \\
\hline std & 11.30 & 11.30 & & 0.05 & & 0.97 & 0.33 & 1.09 & 0.95 & 0.55 & 1.19 & 11.09 \\
\hline \multicolumn{13}{|l|}{$100 \%$} \\
\hline mean & 622.96 & 622.96 & 150.00 & 0.00 & 0.00 & 143.31 & 22.59 & 103.82 & 22.67 & 49.07 & 38.15 & 243.34 \\
\hline std & 22.11 & 22.11 & & & & 2.53 & 0.39 & 1.34 & 0.85 & 0.69 & 3.08 & 21.68 \\
\hline
\end{tabular}


Supplementary Table 25. Health and emissions impacts under different assumption of GHG prices, elasticities, and emissions factors.

\begin{tabular}{lllrr}
$\begin{array}{l}\text { GHG price } \\
\text { (USD/tCO2- } \\
\text { eq) }\end{array}$ & Elasticities & $\begin{array}{l}\text { Emissions } \\
\text { factors }\end{array}$ & $\begin{array}{l}\text { Emissions } \\
\text { reductions } \\
\text { (MtCO2- } \\
\text { eq) }\end{array}$ & $\begin{array}{l}\text { Avoided } \\
\text { deaths } \\
\text { (thousands) }\end{array}$ \\
\hline 52 & mean & mean & -919 & 509.4811 \\
\hline 14 & mean & mean & -312 & 148.6177 \\
78 & mean & mean & $-1,240$ & 741.0997 \\
156 & mean & mean & $-1,890$ & 1299.318 \\
\hline 52 & low & mean & -835 & 460.7 \\
52 & high & mean & $-1,003$ & 555.9 \\
\hline 52 & mean & low & -336 & 332.6 \\
52 & mean & high & $-1,724$ & 667.8 \\
\hline
\end{tabular}


Supplementary Table 26. Deaths avoided (in thousands) by risk factor and region for different GHG prices. Risk factors include changes in red meat consumption (MTC), fruit and vegetable consumption (FVC), underweight (UND), overweight (OVW), obesity (OBS), and all risk factors (ALL_SCN).

\begin{tabular}{|c|c|c|c|c|c|c|c|c|c|}
\hline $\begin{array}{l}\text { GHG price } \\
\text { (USD/tCO2-eq) }\end{array}$ & $\begin{array}{l}\text { Risk } \\
\text { factor }\end{array}$ & World & HIC & AFR_LMIC & AMR_LMIC & EMR_LMIC & EUR_LMIC & SEA_LMIC & WPR_LMIC \\
\hline \multirow{6}{*}{52} & ALL_SCN & 509.4811 & 115.8125 & 18.38673 & 88.33441 & 18.99358 & 40.64441 & 29.52608 & 197.7834 \\
\hline & FVC & 333.2283 & 76.60872 & 11.17678 & 43.07905 & 9.675527 & 25.55164 & 22.23067 & 144.9059 \\
\hline & MTC & 124.2715 & 29.44498 & 7.036621 & 29.90384 & 4.786488 & 8.11943 & 10.64094 & 34.33916 \\
\hline & UND & -63.23228 & -8.748145 & -8.462335 & -4.264067 & -6.346518 & -0.589966 & -22.13816 & -12.68309 \\
\hline & OVW & 14.00953 & 1.534242 & 0.252859 & 0.610791 & 1.051986 & 0.503958 & 3.198377 & 6.857316 \\
\hline & OBS & 104.9312 & 17.67654 & 8.570084 & 20.37904 & 9.959763 & 7.219321 & 15.73774 & 25.38871 \\
\hline \multirow{6}{*}{14} & ALL_SCN & 148.6177 & 32.52525 & 5.821657 & 27.94585 & 5.853609 & 11.4018 & 9.166625 & 55.90295 \\
\hline & FVC & 91.82836 & 20.54344 & 3.312463 & 12.11254 & 2.85232 & 6.981824 & 6.534614 & 39.49116 \\
\hline & MTC & 40.41482 & 8.952069 & 2.416556 & 10.7124 & 1.541221 & 2.358158 & 3.699106 & 10.73531 \\
\hline & UND & -19.54938 & -2.725234 & -2.943756 & -1.291104 & -1.845846 & -0.169121 & -7.005881 & -3.56844 \\
\hline & OVW & 4.152517 & 0.48348 & 0.084335 & 0.181142 & 0.315675 & 0.143447 & 0.991163 & 1.953275 \\
\hline & OBS & 32.11304 & 5.329661 & 2.971957 & 6.369264 & 3.002935 & 2.100588 & 4.961732 & 7.376908 \\
\hline \multirow{6}{*}{78} & ALL_SCN & 741.0997 & 172.9456 & 25.79946 & 123.0031 & 27.38679 & 61.05642 & 41.14885 & 289.7595 \\
\hline & FVC & 496.0474 & 117.0034 & 16.30281 & 62.69351 & 14.51531 & 38.97758 & 31.75378 & 214.801 \\
\hline & MTC & 172.4132 & 42.18689 & 9.42824 & 39.33946 & 6.649532 & 11.94807 & 14.20276 & 48.65825 \\
\hline & UND & -90.6859 & -12.34268 & -11.60282 & -6.183138 & -9.303859 & -0.874927 & -31.26192 & -19.11657 \\
\hline & OVW & 20.48375 & 2.15579 & 0.361292 & 0.895858 & 1.509415 & 0.751699 & 4.561144 & 10.24856 \\
\hline & OBS & 150.489 & 25.46564 & 11.67061 & 28.91629 & 14.29267 & 10.60868 & 22.17746 & 37.35766 \\
\hline \multirow{6}{*}{156} & ALL_SCN & 1299.318 & 335.2745 & 33.27147 & 159.8339 & 47.96059 & 118.659 & 68.60718 & 535.7115 \\
\hline & FVC & 903.5166 & 240.1351 & 20.51511 & 72.53316 & 27.48015 & 78.57867 & 55.89503 & 408.3795 \\
\hline & MTC & 283.8095 & 73.31256 & 14.38145 & 58.49083 & 10.83725 & 22.05868 & 21.36181 & 83.36697 \\
\hline & UND & -153.4115 & -20.50757 & -16.30502 & -7.543788 & -17.21372 & -1.654415 & -52.70755 & -37.47941 \\
\hline & OVW & 36.81867 & 3.570824 & 0.584415 & 1.108584 & 2.648383 & 1.43309 & 7.860665 & 19.61271 \\
\hline & OBS & 248.6584 & 44.02445 & 14.67036 & 39.16676 & 25.0558 & 19.51507 & 37.01235 & 69.21358 \\
\hline
\end{tabular}


Supplementary Table 27. Deaths avoided (in thousands) by risk factor and region for elasticity values. Risk factors include changes in red meat consumption (MTC), fruit and vegetable consumption (FVC), underweight (UND), overweight (OVW), obesity (OBS), and all risk factors combined (ALL_SCN).

\begin{tabular}{|c|c|c|c|c|c|c|c|c|c|}
\hline Elasticities & $\begin{array}{l}\text { Risk } \\
\text { factor }\end{array}$ & World & HIC & AFR_LMIC & AMR_LMIC & EMR_LMIC & EUR_LMIC & SEA_LMIC & WPR_LMIC \\
\hline \multirow{6}{*}{ mean } & ALL_SCN & 509.5 & 115.8 & 18.4 & 88.3 & 19.0 & 40.6 & 29.5 & 197.8 \\
\hline & FVC & 333.2 & 76.6 & 11.2 & 43.1 & 9.7 & 25.6 & 22.2 & 144.9 \\
\hline & MTC & 124.3 & 29.4 & 7.0 & 29.9 & 4.8 & 8.1 & 10.6 & 34.3 \\
\hline & UND & -63.2 & -8.7 & -8.5 & -4.3 & -6.3 & -0.6 & -22.1 & -12.7 \\
\hline & OVW & 14.0 & 1.5 & 0.3 & 0.6 & 1.1 & 0.5 & 3.2 & 6.9 \\
\hline & OBS & 104.9 & 17.7 & 8.6 & 20.4 & 10.0 & 7.2 & 15.7 & 25.4 \\
\hline \multirow{6}{*}{$-10 \%$} & ALL_SCN & 460.7 & 105.0 & 16.7 & 80.1 & 17.4 & 36.7 & 26.6 & 178.2 \\
\hline & FVC & 301.0 & 69.5 & 10.1 & 38.8 & 9.0 & 23.1 & 20.0 & 130.3 \\
\hline & MTC & 112.8 & 26.6 & 6.4 & 27.3 & 4.3 & 7.3 & 9.7 & 31.1 \\
\hline & UND & -57.2 & -7.8 & -7.8 & -3.8 & -5.7 & -0.5 & -20.2 & -11.3 \\
\hline & OVW & 12.6 & 1.4 & 0.2 & 0.5 & 0.9 & 0.5 & 2.9 & 6.1 \\
\hline & OBS & 94.6 & 15.8 & 7.8 & 18.4 & 9.0 & 6.5 & 14.3 & 22.8 \\
\hline \multirow{6}{*}{$+10 \%$} & ALL_SCN & 555.9 & 126.6 & 19.5 & 94.7 & 20.7 & 44.7 & 32.3 & 217.3 \\
\hline & FVC & 363.4 & 83.6 & 11.7 & 45.4 & 10.6 & 28.2 & 24.5 & 159.5 \\
\hline & MTC & 135.6 & 32.3 & 7.6 & 32.5 & 5.2 & 8.9 & 11.6 & 37.5 \\
\hline & UND & -69.5 & -9.6 & -9.3 & -4.7 & -7.0 & -0.7 & -24.2 & -14.0 \\
\hline & OVW & 15.4 & 1.7 & 0.3 & 0.7 & 1.2 & 0.6 & 3.5 & 7.6 \\
\hline & OBS & 115.5 & 19.5 & 9.4 & 22.5 & 10.9 & 7.9 & 17.2 & 28.0 \\
\hline
\end{tabular}


Supplementary Table 28. Deaths avoided (in thousands) by risk factor and region for different emissions factors. Risk factors include changes in red meat consumption (MTC), fruit and vegetable consumption (FVC), underweight (UND), overweight (OVW), obesity (OBS), and all risk factors (ALL_SCN) combined.

\begin{tabular}{|c|c|c|c|c|c|c|c|c|c|}
\hline $\begin{array}{l}\text { Emissions } \\
\text { factors }\end{array}$ & $\begin{array}{l}\text { Risk } \\
\text { factor }\end{array}$ & World & HIC & AFR_LMIC & AMR_LMIC & EMR_LMIC & EUR_LMIC & SEA_LMIC & WPR_LMIC \\
\hline \multirow{6}{*}{ mean } & ALL_SCN & 509.5 & 115.8 & 18.4 & 88.3 & 19.0 & 40.6 & 29.5 & 197.8 \\
\hline & FVC & 333.2 & 76.6 & 11.2 & 43.1 & 9.7 & 25.6 & 22.2 & 144.9 \\
\hline & MTC & 124.3 & 29.4 & 7.0 & 29.9 & 4.8 & 8.1 & 10.6 & 34.3 \\
\hline & UND & -63.2 & -8.7 & -8.5 & -4.3 & -6.3 & -0.6 & -22.1 & -12.7 \\
\hline & OVW & 14.0 & 1.5 & 0.3 & 0.6 & 1.1 & 0.5 & 3.2 & 6.9 \\
\hline & OBS & 104.9 & 17.7 & 8.6 & 20.4 & 10.0 & 7.2 & 15.7 & 25.4 \\
\hline \multirow{6}{*}{ low } & ALL_SCN & 332.6 & 74.4 & 11.6 & 56.0 & 12.7 & 26.8 & 19.6 & 131.5 \\
\hline & FVC & 214.3 & 48.8 & 6.8 & 25.6 & 6.4 & 16.6 & 15.3 & 94.7 \\
\hline & MTC & 74.2 & 17.5 & 4.1 & 17.9 & 2.6 & 4.5 & 6.2 & 21.4 \\
\hline & UND & -48.4 & -7.0 & -6.0 & -3.2 & -4.7 & -0.5 & -16.7 & -10.3 \\
\hline & OVW & 11.1 & 1.2 & 0.2 & 0.5 & 0.8 & 0.4 & 2.5 & 5.5 \\
\hline & OBS & 83.1 & 14.1 & 6.6 & 15.8 & 7.7 & 5.8 & 12.4 & 20.6 \\
\hline \multirow{6}{*}{ high } & ALL_SCN & 667.8 & 156.0 & 23.9 & 113.9 & 25.0 & 54.1 & 37.3 & 257.5 \\
\hline & FVC & 443.4 & 104.8 & 14.9 & 57.3 & 13.2 & 34.4 & 28.1 & 190.7 \\
\hline & MTC & 165.9 & 40.0 & 9.3 & 38.9 & 6.6 & 11.5 & 14.0 & 45.4 \\
\hline & UND & -77.4 & -10.4 & -10.9 & -5.2 & -7.8 & -0.7 & -27.4 & -15.0 \\
\hline & OVW & 16.8 & 1.8 & 0.3 & 0.8 & 1.3 & 0.6 & 3.9 & 8.1 \\
\hline & OBS & 125.3 & 21.0 & 10.5 & 24.4 & 12.0 & 8.6 & 18.9 & 30.0 \\
\hline
\end{tabular}




\section{References}

1. Robinson, S. et al. The International Model for Policy Analysis of Agricultural Commodities and Trade (IMPACT) -- Model description for version 3. (2015).

2. Evenson, R. E. \& Rosengrant, M. W. Productivity Projections for Commodity Marketing Modeling. Paper presented at the final workshop of the International Cooperative Research Project on 'Projections and Policy Implications of Medium and Long-Term Rice Supply and Demand', organized by IFPRI, IRRI, and CCER, Beijing, China, April 23-26, 1995. (1995).

3. Evenson, R. E., Pray, C. \& Rosengrant, M. W. Agricultural Research and Productivity Growth in India. IFPRI Research Report No. 109. (1999).

4. Hoogenboom, G. et al. Decision Support System for Agrotechnology Transfer (DSSAT). ver. 4.5 [CD-ROM]. Univ. Hawaii Honol. Hawaii (2012).

5. Jones, J. W. et al. The DSSAT cropping system model. Eur. J. Agron. 18, 235-265 (2003).

6. USDA. Commodity and Food Elasticities. Retrieved from http://www.ers.usda.gov/Data/Elasticities/. (1998).

7. Green, R. et al. The effect of rising food prices on food consumption: systematic review with meta-regression. BMJ 346, (2013).

8. GAMS. General Algebraic Modeling System (GAMS). GAMS, Washington, D.C. Retrieved from www.gams.com. (2012).

9. World Bank. Manufactures Unit Value Index. (2000). Available at: http://data.worldbank.org/data-catalog/MUV-index.

10. World Bank. Prospects Commodity Markets. (2012). Available at: http://go.worldbank.org/4ROCCIEQ50. 
11. OECD-AMAD. Agricultural market Access Data Base. Retrieved from www.oecd.org/site/amad in 2013. (2010).

12. Narayanan, B. G. \& Walmsley, T. L. Global Trade, Assistance, and Production: The GTAP 7 Data Base, Center for Global Trade Analysis, Purdue University. Available online at: http://www.gtap.agecon.purdue.edu/databases/v7/v7_doco.asp. (2008).

13. International Trade Center. User Guide - Market Access Map: Making Tariffs and Market Access Barriers Transparent. Market Analysis Section, Division of Product and Market Development, International Trade Center, Geneva, December. (2006).

14. Boumellassa, H., Laborde, D. \& Mitaritonna, C. A picture of tariff protection across the world in 2004: MAcMap-HS6, version 2. 903, (Intl Food Policy Res Inst, 2009).

15. OECD. Agricultural Policy Monitoring and Evaluation 2014: OECD Countries. (2014).

16. Food and Agriculture Organization of the United Nations. Food balance sheets: $a$ handbook. (2001).

17. Hawkesworth, S. et al. Feeding the world healthily: the challenge of measuring the effects of agriculture on health. Philos. Trans. R. Soc. Lond. B. Biol. Sci. 365, 3083-3097 (2010).

18. Kearney, J. Food consumption trends and drivers. Philos. Trans. R. Soc. B Biol. Sci. 365, 2793-2807 (2010).

19. Gustavsson, J., Cederberg, C., Sonesson, U., Van Otterdijk, R. \& Meybeck, A. Global food losses and food waste: extent, causes and prevention. (FAO Rome, 2011).

20. Cover, T. M. \& Thomas, J. A. Elements of information theory. (John Wiley \& Sons, 2012).

21. Gerber, P. J. et al. Tackling climate change through livestock: a global assessment of emissions and mitigation opportunities. (FAO, 2013).

22. Tilman, D. \& Clark, M. Global diets link environmental sustainability and human health. Nature 515, 518-522 (2014). 
23. Murray, C. J., Ezzati, M., Lopez, A. D., Rodgers, A. \& Vander Hoorn, S. Comparative quantification of health risks: conceptual framework and methodological issues. Popul. Health Metr. 1, 1 (2003).

24. Lim, S. S. et al. A comparative risk assessment of burden of disease and injury attributable to 67 risk factors and risk factor clusters in 21 regions, 1990-2010: a systematic analysis for the Global Burden of Disease Study 2010. The Lancet 380, 22242260 (2012).

25. Forouzanfar, M. H. et al. Global, regional, and national comparative risk assessment of 79 behavioural, environmental and occupational, and metabolic risks or clusters of risks in 188 countries, 1990-2013: a systematic analysis for the Global Burden of Disease Study 2013. The Lancet 386, 2287-2323 (2015).

26. Murray, C. J. L. et al. GBD 2010: design, definitions, and metrics. Lancet 380, 2063 $2066(2012)$.

27. Lozano, R. et al. Global and regional mortality from 235 causes of death for 20 age groups in 1990 and 2010: a systematic analysis for the Global Burden of Disease Study 2010. The Lancet 380, 2095-2128 (2012).

28. DeSA, U. N. World population prospects: the 2012 revision. Popul. Div. Dep. Econ. Soc. Aff. U. N. Secr. N. Y. (2013).

29. Berrington de Gonzalez, A. et al. Body-Mass Index and Mortality among 1.46 Million White Adults. N. Engl. J. Med. 363, 2211-2219 (2010).

30. Prospective Studies Collaboration et al. Body-mass index and cause-specific mortality in 900000 adults: collaborative analyses of 57 prospective studies. Lancet 373, 1083-1096 (2009).

31. Micha, R., Wallace, S. K. \& Mozaffarian, D. Red and processed meat consumption and risk of incident coronary heart disease, stroke, and diabetes mellitus: a systematic review and meta-analysis. Circulation 121, 2271-2283 (2010). 
32. Chen, G.-C., Lv, D.-B., Pang, Z. \& Liu, Q.-F. Red and processed meat consumption and risk of stroke: a meta-analysis of prospective cohort studies. Eur. J. Clin. Nutr. 67, 91-95 (2013).

33. Dauchet, L., Amouyel, P. \& Dallongeville, J. Fruit and vegetable consumption and risk of stroke: a meta-analysis of cohort studies. Neurology 65, 1193-1197 (2005).

34. Dauchet, L., Amouyel, P., Hercberg, S. \& Dallongeville, J. Fruit and vegetable consumption and risk of coronary heart disease: a meta-analysis of cohort studies. J. Nutr. 136, 2588-2593 (2006).

35. WCRF/AICR. Food, Nutrition, Physical Activity, and the Prevention of Cancer: A Global Perspective. (AICR, 2007).

36. WCRF/AICR. Continuous Update Project Report. Food, Nutrition, Physical Activity, and the Prevention of Pancreatic Cancer. (2012).

37. Feskens, E. J. M., Sluik, D. \& van Woudenbergh, G. J. Meat consumption, diabetes, and its complications. Curr. Diab. Rep. 13, 298-306 (2013).

38. Li, M., Fan, Y., Zhang, X., Hou, W. \& Tang, Z. Fruit and vegetable intake and risk of type 2 diabetes mellitus: meta-analysis of prospective cohort studies. BMJ Open 4, e005497 (2014).

39. Lloyd, S. J., Kovats, R. S. \& Chalabi, Z. Climate change, crop yields, and undernutrition: development of a model to quantify the impact of climate scenarios on child undernutrition. Environ. Health Perspect. 119, 1817-1823 (2011).

40. Smith, L. C. \& Haddad, L. J. Explaining child malnutrition in developing countries: A cross-country analysis. 111, (Intl Food Policy Res Inst, 2000).

41. Willett WC, Manson JE, Stampfer MJ \& et al. Weight, weight change, and coronary heart disease in women: Risk within the 'normal' weight range. JAMA 273, 461-465 (1995). 
42. Asia Pacific Cohort Studies Collaboration. Body mass index and cardiovascular disease in the Asia-Pacific Region: an overview of 33 cohorts involving 310000 participants. Int. J. Epidemiol. 33, 751-758 (2004).

43. Song, Y.-M., Sung, J., Smith, G. D. \& Ebrahim, S. Body Mass Index and Ischemic and Hemorrhagic Stroke A Prospective Study in Korean Men. Stroke 35, 831-836 (2004).

44. Rexrode KM, Hennekens $\mathrm{CH}$, Willett WC \& et al. A prospective study of body mass index, weight change, and risk of stroke in women. JAMA 277, 1539-1545 (1997).

45. Calle, E. E., Rodriguez, C., Walker-Thurmond, K. \& Thun, M. J. Overweight, obesity, and mortality from cancer in a prospectively studied cohort of U.S. adults. N. Engl. J. Med. 348, 1625-1638 (2003).

46. Reeves, G. K. et al. Cancer incidence and mortality in relation to body mass index in the Million Women Study: cohort study. BMJ 335, 1134 (2007).

47. Parr, C. L. et al. Body-mass index and cancer mortality in the Asia-Pacific Cohort Studies Collaboration: pooled analyses of 424,519 participants. Lancet Oncol. 11, 741-752 (2010).

48. Calle, E. E. \& Kaaks, R. Overweight, obesity and cancer: epidemiological evidence and proposed mechanisms. Nat. Rev. Cancer 4, 579-591 (2004).

49. Willett, W. C., Dietz, W. H. \& Colditz, G. A. Guidelines for healthy weight. N. Engl. J. Med. 341, 427-434 (1999).

50. Chiolero, A. \& Kaufman, J. S. Metabolic mediators of body-mass index and cardiovascular risk. The Lancet 383, 2042 (2014).

51. Yusuf, S. et al. Effect of potentially modifiable risk factors associated with myocardial infarction in 52 countries (the INTERHEART study): case-control study. Lancet 364, 937-952 (2004).

52. Khaw, K.-T. et al. Combined Impact of Health Behaviours and Mortality in Men and Women: The EPIC-Norfolk Prospective Population Study. PLoS Med 5, e12 (2008). 
53. Dam, R. M. van, Li, T., Spiegelman, D., Franco, O. H. \& Hu, F. B. Combined Impact of Lifestyle Factors on Mortality: Prospective Cohort Study in US Women. BMJ 337, 742745 (2008).

54. Huxley, R. R. et al. The impact of dietary and lifestyle risk factors on risk of colorectal cancer: a quantitative overview of the epidemiological evidence. Int. J. Cancer J. Int. Cancer 125, 171-180 (2009).

55. Nechuta, S. J. et al. Combined impact of lifestyle-related factors on total and causespecific mortality among Chinese women: prospective cohort study. PLoS Med. 7, (2010). 